\title{
Modeling surf zone tracer plumes: \\ 2. Transport and dispersion
}

\author{
David B. Clark, ${ }^{1,2}$ Falk Feddersen, ${ }^{1}$ and R. T. Guza ${ }^{1}$ \\ Received 11 April 2011; revised 26 August 2011; accepted 29 August 2011; published 18 November 2011.
}

[1] Five surf zone dye tracer releases from the HB06 experiment are simulated with a tracer advection diffusion model coupled to a Boussinesq surf zone model (funwaveC). Model tracer is transported and stirred by currents and eddies and diffused with a breaking wave eddy diffusivity, set equal to the breaking wave eddy viscosity, and a small $\left(0.01 \mathrm{~m}^{2} \mathrm{~s}^{-1}\right)$ background diffusivity. Observed and modeled alongshore parallel tracer plumes, transported by the wave driven alongshore current, have qualitatively similar cross-shore structures. Although the model skill for mean tracer concentration is variable (from negative to 0.73) depending upon release, cross-shore integrated tracer moments (normalized by the cross-shore tracer integral) have consistently high skills $(\approx 0.9)$. Modeled and observed bulk surf zone cross-shore diffusivity estimates are also similar, with 0.72 squared correlation and skill of 0.4 . Similar to the observations, the model bulk (absolute) cross-shore diffusivity is consistent with a mixing length parameterization based on low-frequency $(0.001-0.03 \mathrm{~Hz})$ eddies. The model absolute cross-shore dispersion is dominated by stirring from surf zone eddies and does not depend upon the presence of the breaking wave eddy diffusivity. Given only the bathymetry and incident wave field, the coupled Boussinesq-tracer model qualitatively reproduces the observed cross-shore absolute tracer dispersion, suggesting that the model can be used to study surf zone tracer dispersion mechanisms.

Citation: Clark, D. B., F. Feddersen, and R. T. Guza (2011), Modeling surf zone tracer plumes: 2. Transport and dispersion, J. Geophys. Res., 116, C11028, doi:10.1029/2011JC007211.

\section{Introduction}

[2] The rates and mechanisms of surf zone horizontal tracer (e.g., pollution, nutrients, sediment, and larvae) dispersion are understood poorly, and numerical models may be useful for investigating the underlying dispersion processes. However, numerical surf zone tracer models have not been validated, a necessary step before investigating dispersion mechanisms.

[3] Surf zone tracer dispersion has been modeled analytically and numerically. Simple Fickian analytic models were used to estimate bulk surf zone diffusivity from field data [Harris et al., 1963; Inman et al., 1971; Clarke et al., 2007; Clark et al., 2010]. Fickian models may be able to predict bulk surf zone tracer dispersion with the appropriate diffusion coefficient. However, surf zone diffusivity values are poorly known, and diffusivity parameterizations have not been validated over a broad range of conditions. Coupled tracer and (wave-averaged) circulation models have been sparingly used to simulate tracer transport in the nearshore and surf zone [Tao and JianHua, 2006; Issa et al., 2010], but com-

\footnotetext{
${ }^{1}$ Scripps Institution of Oceanography, University of California, San Diego, La Jolla, California, USA.

${ }^{2}$ Now at Woods Hole Oceanographic Institution, Woods Hole, Massachusetts, USA.

Copyright 2011 by the American Geophysical Union. 0148-0227/11/2011JC007211
}

parisons with observations are very limited [Rodriguez et al., 1995].

[4] Scaling arguments [Harris et al., 1963; Inman et al., 1971] and an idealized model [Feddersen, 2007; Henderson, 2007] suggest that the bulk (averaged over many waves) cross-shore tracer diffusivity $\kappa_{x x}$ from turbulent mixing at the front face of broken waves (bores) scales as $\kappa_{x x} \propto H_{\mathrm{s}}^{2} T_{\mathrm{m}}^{-1}$, where $H_{\mathrm{s}}$ and $T_{\mathrm{m}}$ are the incident significant wave height and mean period, respectively. However, this scaling had marginal correlation $\left(r^{2}=0.32\right)$ when compared with recently observed bulk cross-shore dye diffusivities [Clark et al., 2010]. Stirring due to low-frequency $(f<0.03 \mathrm{~Hz})$ horizontal surf zone eddies may induce a significant amount of cross-shore tracer dispersion. Higher correlation $\left(r^{2}=0.59\right)$ was found for a surf zone-eddy mixing length scaling $\kappa_{x x} \propto$ $\overline{\mathcal{V}}_{\text {rot }}^{\text {(IG) }} L_{x}$, where $L_{x}$ is the surf zone width and $\overline{\mathcal{V}}_{\text {rot }}^{\text {(IG) is a }}$ surf zone (cross-shore) averaged bulk infragravity (0.004 $0.03 \mathrm{~Hz}$ ) eddy velocity, suggesting that low-frequency eddies may be a primary dispersion mechanism [Clark et al., 2010]. An undertow-induced cross-shore shear dispersion scaling [Pearson et al., 2009] was not found to be applicable [Clark et al., 2010]. Overall, the mechanisms of tracer dispersion and their relative importance are not well understood.

[5] Time-dependent wave-resolving surf zone models (most commonly Boussinesq models), include the broad range of processes, from individual breaking waves to lowfrequency eddies and mean currents, required for investigating surf zone tracer dispersion mechanisms. Boussinesq surf 

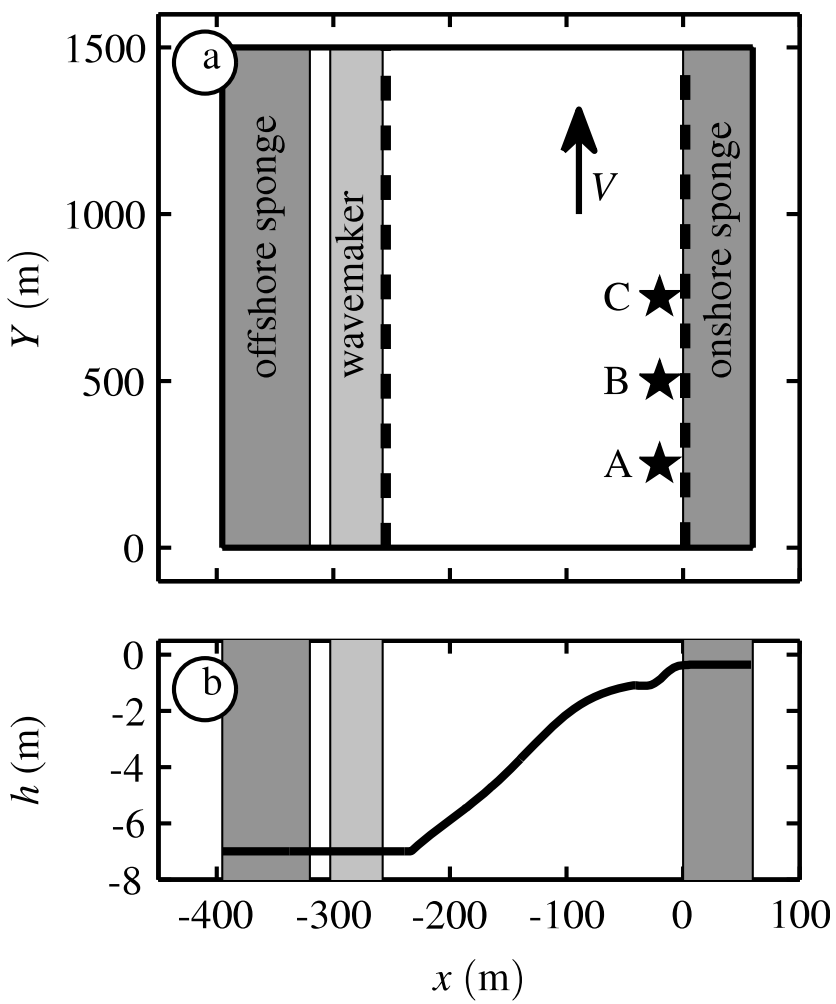

Figure 1. (a) Plan view of a typical model domain (R4 example). The cross-shore distance from the "shoreline" is $x$, and $Y$ is the alongshore coordinate. Gray regions indicate sponge layers and the wave maker. The cross-shore tracer domain (dashed lines) is bounded by the offshore wave maker and the onshore sponge layer. Stars indicate release locations for model tracers A $\left(Y_{\mathrm{rl}}=250 \mathrm{~m}\right), \mathrm{B}\left(Y_{\mathrm{rl}}=500 \mathrm{~m}\right)$, and $\mathrm{C}\left(Y_{\mathrm{rl}}=750 \mathrm{~m}\right)$, and the arrow indicates the direction of the mean alongshore current $V$. (b) Typical model crossshore bathymetry $h$ versus $x$ (R4 example), with a flat region at $7 \mathrm{~m}$ depth for the offshore sponge layer and wave maker and a $0.3 \mathrm{~m}$ depth flat region for the onshore sponge layer.

zone models, solving an extended version of the nonlinear shallow water equations with weak nonlinearity and dispersion [e.g., Peregrine, 1967; Nwogu, 1993; Wei et al., 1995], have been used to examine surf zone drifter dispersion in directionally spread random wave fields [Johnson and Pattiaratchi, 2006; Spydell and Feddersen, 2009; Geiman et al., 2011], but have not been used for surf zone tracer modeling. Finite crest length wave breaking within Boussinesq models provide a (vertical) vorticity source for forcing horizontal eddies [Peregrine, 1998] at a range of length scales, which induced surf zone drifter dispersion at scales between 20 and $200 \mathrm{~m}$ [Spydell and Feddersen, 2009]. Surf zone drifters duck under, and are not dispersed by entrainment in, the front face of breaking waves [e.g., Schmidt et al., 2003, 2005]. By resolving individual wave breaking, Boussinesq models also provide a mechanisms for breaking waves to mix tracer. Thus, a depth-averaged tracer advection diffusion equation coupled to a Boussinesq model contains both stirring by the horizontal eddy field (e.g., vertical vorticity) and the breaking wave mixing mechanisms.

[6] Here, five surf zone tracer releases from the HB06 experiment in Huntington Beach, California [Clark et al.,
2010] are simulated with the coupled tracer and Boussinesq model funwaveC. The Boussinesq model is described by Feddersen et al. [2011] (hereinafter referred to as Part 1), and compared with Eulerian wave and current observations. The model reproduces the observed significant wave height and (except for one release) alongshore currents. Low-frequency eddies are well modeled in the infragravity frequency $(f)$ band $(0.004<f<0.03 \mathrm{~Hz})$, but are overpredicted by a factor of 2 in the very low frequency (VLF, $0.001<f<0.004 \mathrm{~Hz}$ ) band. The HB06 tracer experiments and previous results are summarized in section 2. The tracer model and averaging method are described in section 3 .

[7] Mean tracer concentrations are well modeled for 3 out of 5 releases (section 4). For all releases, model skills for cross-shore integrated tracer first and second moments are high, and the model reproduces the observed bulk cross-shore surf zone diffusivity (section 5). The causes of model-data mismatch for mean tracer and alongshore tracer transport are discussed in sections 6.1 and 6.2, respectively. The downstream dilution of the modeled mean plume is consistent with a Fickian analytic solution (section 6.3). The effect of the modeled breaking wave eddy diffusivity on crossshore tracer dispersion is discussed in section 6.4. Mixing length scalings for modeled bulk cross-shore diffusivity $\kappa_{x x}$, using bulk low-frequency eddy velocities, are examined in section 6.5. The results are summarized in section 7 .

\section{HB06 Observations and Dye Releases}

[8] The predominant south swell during the HB06 experiment drove strong alongshore currents upcoast (toward the northwest). Waves and currents were measured on a $140 \mathrm{~m}$ long cross-shore array of 7 bottom mounted tripods, denoted F1-F7 from near the shoreline to roughly $4 \mathrm{~m}$ water depth (Part 1, Figure 1). The observations at F2 were often poor quality, and are not included in the subsequent analysis. Hourly significant wave heights $H_{\mathrm{s}}$ ranged from 0.41 to $1.02 \mathrm{~m}$ during the tracer releases, with mean wave periods $T_{\mathrm{m}}$ from 9 to $9.9 \mathrm{~s}$, and directional spreads $\sigma_{\theta}$ from $15^{\circ}$ to $23^{\circ}$. Mean (in time) alongshore currents $V(x)$ (where $x$ is the crossshore distance from the shoreline) were generally maximum near mid surf zone, except for one release with maximum $V(x)$ near the shoreline. Eulerian wave and current observations are described by Clark et al. [2010] and compared with the funwaveC Boussinesq model in Part 1.

[9] Five continuous dye tracer releases (denoted R1, R2, R3, R4, and R6) were performed on different days [Clark et al., 2010]. Dye tracer was injected $0.5 \mathrm{~m}$ above the bed in roughly $1 \mathrm{~m}$ water depth (4-54 $\mathrm{m}$ from the shoreline), at rates between $1.3-7.1 \mathrm{~mL} \mathrm{~s}^{-1}\left(263-1489 \mathrm{ppb} \mathrm{m}^{3} \mathrm{~s}^{-1}\right)$. The tracer was advected downstream with the mean alongshore current, forming shore parallel plumes, and measured near the surface for between 40 and $121 \mathrm{~min}$ (depending on the release) with a jet ski mounted fluorometer system [Clark et al., 2009].

[10] Visual observation indicated rapid vertical tracer mixing (tracer reaching the surface within several meters of the source), and patchy and highly variable tracer plumes. Dye was sampled on repeated cross-shore transects at 3-9 downstream locations, between 16 and $565 \mathrm{~m}$ from the tracer source. With increasing downstream distance $y$ from the dye source, the mean cross-shore tracer profile $D(x, y)$ peak 
Table 1. Model Tracer Release Parameters: Input Tracer Flux $M_{0}$ and Cross-Shore Release Location $x_{\mathrm{rl}}$

\begin{tabular}{ccc}
\hline Release & $\begin{array}{c}M_{0} \\
\left(\mathrm{pp} \mathrm{m}^{3} \mathrm{~s}^{-1}\right)\end{array}$ & $\begin{array}{c}x_{\mathrm{rl}} \\
(\mathrm{m})\end{array}$ \\
\hline R1 & 263 & -54 \\
R2 & 647 & -13 \\
R3 & 1256 & -10 \\
R4 & 1489 & -22 \\
R6 & 485 & -12 \\
\hline
\end{tabular}

concentrations decreased and cross-shore widths increased. The cross-shore profiles were often shoreline attached, roughly resembling a half-Gaussian, with a maxima near the shoreline. Bulk cross-shore surf zone diffusivities $\kappa_{x x}$ were estimated from the downstream evolution of the plume squared cross-shore length scale, and varied between 0.5 and $2.5 \mathrm{~m}^{2} \mathrm{~s}^{-1}$ [Clark et al., 2010].

\section{Surf Zone Tracer Modeling and Analysis}

\subsection{Tracer Model Description}

[11] The 5 tracer releases analyzed by Clark et al. [2010] are simulated with a time-dependent wave-resolving Boussinesq model (funwaveC, Part 1). The model bathymetry is based on the observed alongshore-averaged survey bathymetry (Figure 1b). Waves matching the observed incident angle, directional spread, and energy spectrum are generated by the model wave maker, and propagate toward the shore where they "break" and dissipate (by the breaking eddy viscosity $\nu_{\text {br }}$ ). Model wave breaking drives alongshore currents and low-frequency $(f<0.03 \mathrm{~Hz})$ surf zone eddies. The observed significant wave height $H_{\mathrm{s}}(x)$, mean alongshore current $V(x)$, and bulk rotational infragravity (IG) velocities $\mathcal{V}_{\text {rot }}^{(\mathrm{IG})}(x)$ are modeled with high skill. Bulk very low frequency (VLF) rotational velocities were overpredicted by about a factor of 2 (Part 1).

[12] A depth-averaged tracer module, coupled to the timedependent Boussinesq model funwaveC, allows for three separate noninteracting tracers (denoted A, B, and C) released at different locations. Each tracer samples a different part of the flow field, increasing the degrees of freedom for quantities averaged over the statistics of all three tracers. Model tracer evolves according to an advection-diffusion equation,

$$
\begin{aligned}
\frac{\partial[(h+\eta) d]}{\partial t}+\nabla \cdot[(h+\eta) \boldsymbol{u} d]= & \nabla \cdot\left[\left(\kappa_{\mathrm{br}}+\kappa_{0}\right)(h+\eta) \nabla d\right] \\
& +M_{0} \delta\left(x-x_{\mathrm{rl}}\right) \delta\left(Y-Y_{\mathrm{rl}}\right)
\end{aligned}
$$

where $d$ is the tracer concentration (in ppb), $h$ is the still water depth, $\eta$ is the free surface elevation, $\kappa_{\mathrm{br}}$ is the breaking wave eddy diffusivity, $\kappa_{0}$ is the background diffusivity, $\nabla$ is the two-dimensional horizontal gradient operator, and $\boldsymbol{u}$ is the model horizontal velocity vector, which for small $k h$ is approximately the depth-averaged velocity. Tracer is injected into the model at $\left(x=x_{\mathrm{rl}}, Y=Y_{\mathrm{rl}}\right)$ with the input flux $M_{0}(\delta$ is the Kronecker delta function).

[13] In (1), $\kappa_{\mathrm{br}}$ is set equal to the breaking wave eddy viscosity $\nu_{\text {br }}$ (e.g., momentum and tracer are assumed to mix identically), and the background diffusivity $\kappa_{0}=0.01 \mathrm{~m}^{2} \mathrm{~s}^{-1}$, is two orders of magnitude smaller than the observed bulk $\kappa_{x x}$. The $\kappa_{\mathrm{br}}$ is nonzero only on the front face of a breaking wave (bore), whereas $\kappa_{0}$ is applied everywhere. The inclusion of the breaking eddy viscosity allows the breaking wave mixing mechanism discussed by Feddersen [2007] to be examined relative to other tracer dispersion mechanisms.

[14] The vertically integrated Boussinesq and tracer models lack cross-shore dispersion by vertically sheared currents (i.e., undertow). However, this mechanism was not found to be significant in a natural surf zone with directionally spread waves [Clark et al., 2010], and rapid vertical mixing [Feddersen and Trowbridge, 2005; Ruessink, 2010; Feddersen, 2011] implies little vertical tracer structure within the surf zone. However, vertical structure may be important seaward of the surf zone [Kim and Lynett, 2010].

[15] The cross-shore tracer domain (dashed lines, Figure 1a) is embedded in the full Boussinesq model domain. The offshore tracer boundary (set to $d=0 \mathrm{ppb}$ ) is located just onshore of the wave maker region between $x=232$ and $260 \mathrm{~m}$ from the shoreline, depending upon release. The onshore tracer boundary is typically located $\approx 5 \mathrm{~m}$ onshore of the start of the sponge layer (the depth of the flat region is $\left.h_{0}=0.2-0.35 \mathrm{~m}\right)$, where a no-flux boundary condition is applied. In contrast to the $\eta$ and $\boldsymbol{u}$ periodic alongshore boundary conditions, the tracer alongshore boundary conditions (at both ends of the $1500 \mathrm{~m}$ alongshore domain) are open, allowing tracer to advect out of the domain (Figure 1a). The alongshore tracer boundary conditions affect tracer concentrations within approximately $25 \mathrm{~m}$ of the boundary, and these regions are excluded from the analysis.

[16] The model spins up for $2000 \mathrm{~s}$ before starting continuous releases of tracers $\mathrm{A}, \mathrm{B}$, and $\mathrm{C}$ at alongshore locations $Y_{\mathrm{rl}}=250,500$, and $750 \mathrm{~m}$, respectively, from the upstream boundary (Figure 1a). Model and observed cross-shore release locations $x_{\mathrm{rl}}$ and tracer injection rates $M_{0}$ are equal (Table 1). Model instantaneous tracer concentrations $d^{(\mathrm{A}, \mathrm{B}, \mathrm{C})}$, sea surface elevation $\eta$, cross-shore and alongshore currents ( $u$ and $v$ ), and breaking wave eddy diffusivity $\kappa_{\text {br }}$ are output every $2 \mathrm{~s}$ over the entire domain.

\subsection{Model Tracer Analysis: Averaging}

[17] The model tracer advects downstream with the mean alongshore current forming a shore-parallel plume that widens with downstream distance. Instantaneous $d^{(\mathrm{A})}$ model tracer plumes (Figures 2a, 2c, and 2e) are variable and patchy, with eddy-like tracer structure seaward of the surf zone $(\mathrm{x}<-100 \mathrm{~m})$. The cross-shore structure of modeled lowfrequency rotational motions (i.e., eddies) is discussed in Part 1.

[18] The $D^{(\mathrm{A})}(x, y), D^{(\mathrm{B})}(x, y)$, and $D^{(\mathrm{C})}(x, y)$ represent mean modeled tracers $\mathrm{A}, \mathrm{B}$, and $\mathrm{C}$, time averaged in a fixed reference frame $(x=0 \mathrm{~m}$ at the shoreline and $y=0 \mathrm{~m}$ at the release location) between 6000 and 14,000 s after the tracer release started. Time averaging begins once the tracer plume has reached quasi-equilibrium (see Figure 3). The averaging times used for the observed means $D^{\text {(obs) }}$ are limited by instrument and environmental parameters to between 40 and $120 \mathrm{~min}$. The model averages are over $133 \mathrm{~min}(8000 \mathrm{~s})$ after tracer is equilibrated (Figure 3). Stability of the numerical results is further increased by averaging statistics over tracers A, B, and C. Averages over one $5600 \mathrm{~s}$ wave maker recurrence cycle (Part 1) are nearly identical to the $8000 \mathrm{~s}$ averages presented here, suggesting the wave maker recurrence does not effect the tracer results significantly. The observed $D^{(\text {obs })}$ 

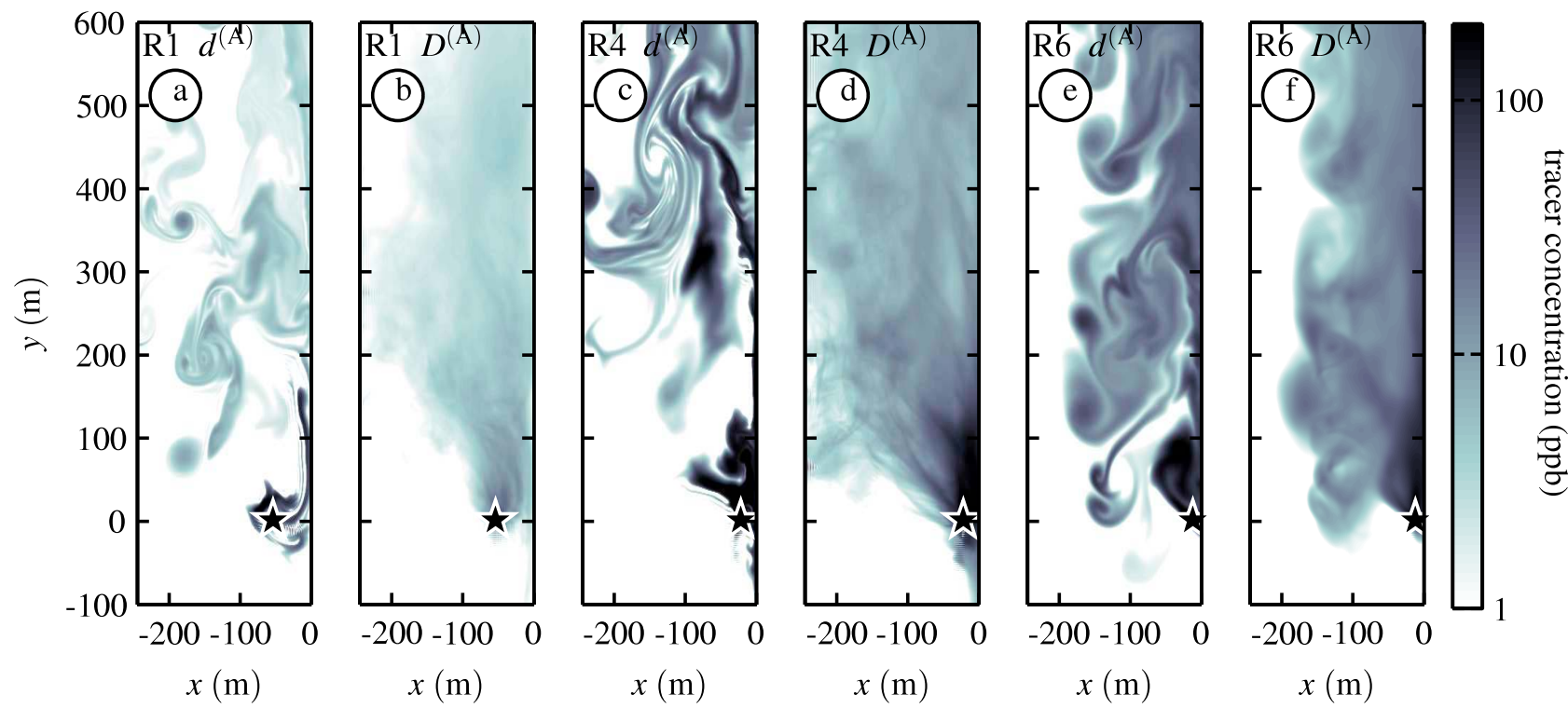

Figure 2. (a, c, and e) Instantaneous $d^{(\mathrm{A})}$ and (b, d, and f) mean $D^{(\mathrm{A})}$ (time average over 6000-14,000 s after each tracer release begins) modeled tracer A concentration as a function of $x$, the cross-shore distance from the "shoreline," and $y$, the alongshore distance from the dye source, for R1 (Figures 2a and 2b), R4 (Figures $2 \mathrm{c}$ and 2d), and R6 (Figures $2 \mathrm{e}$ and 2f). In each panel the black star indicates the cross-shore release location $\left(x_{\mathrm{r}}\right.$, Table 1$)$.

(this notation differs slightly from Clark et al. [2010]) and model $D^{(\mathrm{A}, \mathrm{B}, \mathrm{C})}$ mean plumes are time averaged in fixed coordinates (i.e., absolute averaged), which includes any plume meandering in the resulting (absolute) diffusivity estimates. Relative averaging (e.g., in center of mass coordinates [Csanady, 1973]), which separates plume meandering from smaller-scale mixing, is not used here because the interpretation of relative averages is unclear near the shoreline boundary [Clark et al., 2010].

[19] Mean tracer $D^{(\hat{A})}$ plumes (Figures $2 \mathrm{~b}, 2 \mathrm{~d}$, and $2 \mathrm{f}$ ) are much smoother than the instantaneous tracer (Figures 2a, 2c, and 2e). The absolute concentration (in ppb) varies between model releases (relative shades of gray between panels in Figure 2), due to different tracer injection rates (Table 1), different $V$ magnitudes (stronger $V$ decreases tracer concentrations for a given injection rate), and varying amount of cross-shore dispersion.

\section{Mean Cross-Shore Tracer Profiles and Alongshore Tracer Transport}

\subsection{Mean Cross-Shore Tracer Profiles}

[20] Model $D^{(\mathrm{A})}$ and observed $D^{(\mathrm{obs})}$ mean tracer profiles at three representative downstream $y$ are shown for all releases in Figure 4. $D^{(\mathrm{A})}$ and $D^{(\mathrm{obs})}$ profiles for R3, R4, and R6 are usually shoreline attached (maxima at or near the shoreline), with decreasing peak concentrations and increasing cross-shore widths with downstream distance $y$ (Figures $4 \mathrm{c}-4 \mathrm{e}$ ). The mean tracer concentration skill for each transect is estimated by $1-\left\langle\left(D^{(\mathrm{obs})}(x, y)-D^{(\mathrm{A}, \mathrm{B}, \mathrm{C})}(x, y)\right)^{2}\right\rangle_{x, y} /$ $\left\langle D^{2 \text { (obs) }}(x, y)\right\rangle_{x, y}$, where \langle\rangle$_{x, y}$ is the mean over $x$ and $y$, for regions where $D^{\text {(obs) }}>5 \mathrm{ppb}$ (thus avoiding relatively large instrument noise at low concentrations). Mean R3, R4 and R6 skills, averaged over all transects and the three model tracers in each release, are between 0.5 and 0.73 (Table 2), consistent with the qualitative agreement in Figures $4 \mathrm{c}-4 \mathrm{e}$.

[21] For release R1, the magnitudes and shapes of $D^{(\mathrm{A})}$ and $D^{\text {(obs) }}$ are roughly similar, and both model and observed mean tracer spread in the cross-shore with downstream distance (Figure 4a). However, at $y=56$ and $107 \mathrm{~m}$ the $D^{(\mathrm{obs})}$ maximum is farther to the shoreline than for $D^{(\mathrm{A})}$ (Figure 4a), which may be explained by seaward advection of the observed plume [Clark et al., 2010]. This cross-shore displacement between $D^{\text {(A) }}$ and $D^{\text {(obs) }}$ maxima results in negative skill for R1 (Table 2), despite the similarity in shape.

[22] The R2 $D^{(\mathrm{A})}$ disperses similarly to $D^{(\mathrm{obs})}$, however the $D^{(\mathrm{A})}$ magnitudes are significantly larger than $D^{\text {(obs) }}$

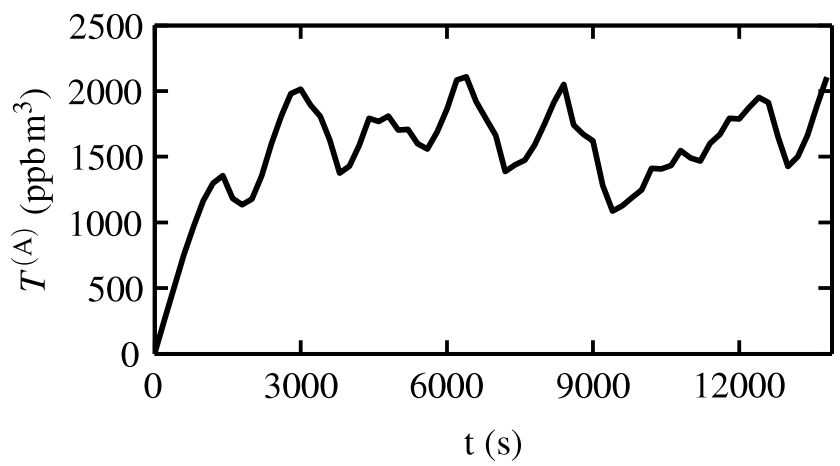

Figure 3. The $\mathrm{R} 4$ total tracer A volume $T^{(\mathrm{A})}$ versus time after the tracer release began, where $T^{(\mathrm{A})}(t)=\iint(h+n)$ $\left.d^{(\mathrm{A})}(t) d y d x\right)$ is integrated over the entire cross-shore tracer domain and from the upstream model boundary to $250 \mathrm{~m}$ downstream of the tracer source (where R4 diffusivities are estimated). For $t>3000 \mathrm{~s}$ the quasi-steady-state $T^{(\mathrm{A})}$ oscillates about a mean. The $\mathrm{R} 4 T^{(\mathrm{A})}$ is representative of other tracers and releases. 

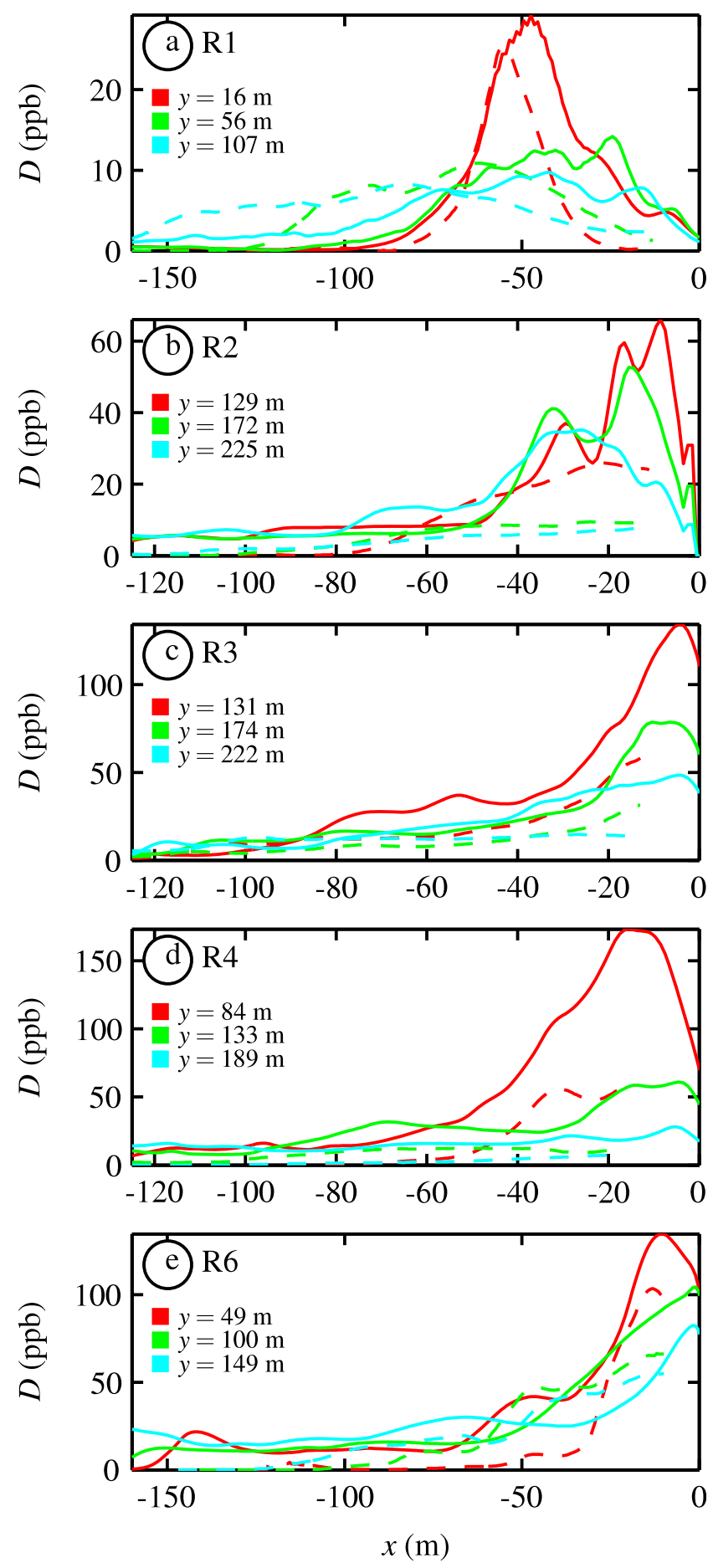

Figure 4. Modeled $D^{(\mathrm{A})}$ (solid) and observed $D^{(\mathrm{obs})}$ (dashed) mean tracer profiles versus $x$ for (a) R1, (b) R2, (c) R3, (d) R4, and (e) R6, with alongshore distance $y$ from the source indicted by the legend in each panel. Observed transects extend from seaward of the tracer plume to the inner transect edge $x_{\text {in }}$.

(Figure $4 b$ ) which results in negative skill (Table 2). The differences in mean tracer magnitude are most pronounced near the shoreline where $D^{(\mathrm{A})}$ are often 2-5 times larger than $D^{\text {(obs) }}$ (Figure $4 \mathrm{~b}$ ).

\subsection{Alongshore Tracer Transport}

[23] Model $M^{(\mathrm{A}, \mathrm{B}, \mathrm{C})}(y)$ and observed $M^{(\mathrm{obs})}(y)$ alongshore tracer transports are [Clark et al., 2010]

$$
M(y)=\int_{x_{\mathrm{F}}}^{x_{\text {in }}} h(x) V(x, y) D(x, y) d x,
$$

where $x_{\text {in }}$ is the observed inner transect edge (i.e., where observations end near the shoreline, Figure 4), $x_{\mathrm{F} 7}$ is the F7 location (the farthest seaward velocity observation), and $V(x, y)$ is the mean alongshore current averaged over the same times as $D(x, y)$. Note that the model $M^{(\mathrm{A}, \mathrm{B}, \mathrm{C})}$ uses alongshore varying $V(x, y)$ while the observations assume alongshore uniform $V(x)$ as measured on the cross-shore array. The model $V(x, y)$ vary weakly alongshore (Part 1), and using alongshore averaged model $V(x)$ does not change $M^{(\mathrm{A}, \mathrm{B}, \mathrm{C})}$ significantly. The $x_{\text {in }}$ range from -17 to $-10 \mathrm{~m}$, and $x_{\mathrm{F} 7}$ range from -146 to $-162 \mathrm{~m}$ from the shoreline. This $M(y)$ estimate excludes the region shoreward of $x_{\text {in }}$ and seaward of $x_{\mathrm{F} 7}$, and excludes alongshore eddy tracer fluxes by using time averaged $V$ and $D$.

[24] The $M^{(\mathrm{A}, \mathrm{B}, \mathrm{C})}$ and $M^{(\mathrm{obs})}$ have roughly similar structure and decrease slightly at large $y$, except the overestimated $M^{(\mathrm{A}, \mathrm{B}, \mathrm{C})}$ in R3 (Figure 5). Estimates between individual $M^{(\mathrm{A})}, M^{(\mathrm{B})}$, and $M^{(\mathrm{C})}$, sometimes vary by $50 \%$. The model tracer input flux is equal to the observed dye release flux $M^{(\mathrm{obs})}(y=0)$ (circles in Figure 5), however the $M^{(\mathrm{A}, \mathrm{B}, \mathrm{C})} \mathrm{do}$ not necessarily match at the source and are not conserved downstream. The difference between the observed input flux $(y=0$, circles in Figure 5) and observed and modeled downstream transport $M^{\text {(obs) }}(y>0)$ may be due to neglected alongshore eddy fluxes in (2) or to tracer transported onshore of $x_{\text {in }}\left(\right.$ e.g., $\mathrm{R} 3 D^{(\mathrm{A})}$ at $x>-15 \mathrm{~m}$ in Figure $4 \mathrm{c}$ ) or offshore of $x_{\mathrm{F} 7}$. For the model, this is examined in section 6.2.

\section{Cross-Shore Integrated Tracer Moments and Bulk Surf Zone Diffusivity $\kappa_{x x}$}

\subsection{Definitions}

[25] Observed and modeled cross-shore tracer plume structures are compared using cross-shore integrated surface tracer moments, which are consistent with a Fickian framework [Clark et al., 2010]. These moments are normalized by the total tracer (cross-shore $D$ integral), and thus independent of absolute concentration. The surface center of mass $\mu$ is the $D$ first moment [Clark et al., 2010]

$$
\mu(y)=\frac{\int_{x_{\text {out }}}^{x_{\text {in }}} x D(x, y) d x}{\int_{x_{\text {out }}}^{x_{\text {in }}} D(x, y) d x}
$$

where $x_{\text {out }}$, the offshore extent of the observed transects, varied from -105 to $-298 \mathrm{~m}$ over all transects. The jet ski

Table 2. Mean Tracer Concentration Skill ${ }^{\mathrm{a}}$

\begin{tabular}{lllll}
\hline R1 & R2 & R3 & R4 & R6 \\
\hline-2.70 & -8.89 & 0.70 & 0.50 & 0.73 \\
\hline
\end{tabular}

${ }^{\mathrm{a}}$ For each release, the mean tracer concentration skill $1-\left\langle\left(D^{\text {(obs) }}(x, y)-\right.\right.$ $\left.\left.D^{(\mathrm{A}, \mathrm{B}, \mathrm{C})}(x, y)\right)^{2}\right\rangle_{x, y} /\left\langle D^{2 \text { (obs) }}(x, y)\right\rangle_{x, y}$, averaged over all observed transects where $D^{\text {(obs) }}>5 \mathrm{ppb}$ and all three (A, B, and C) model tracers. 

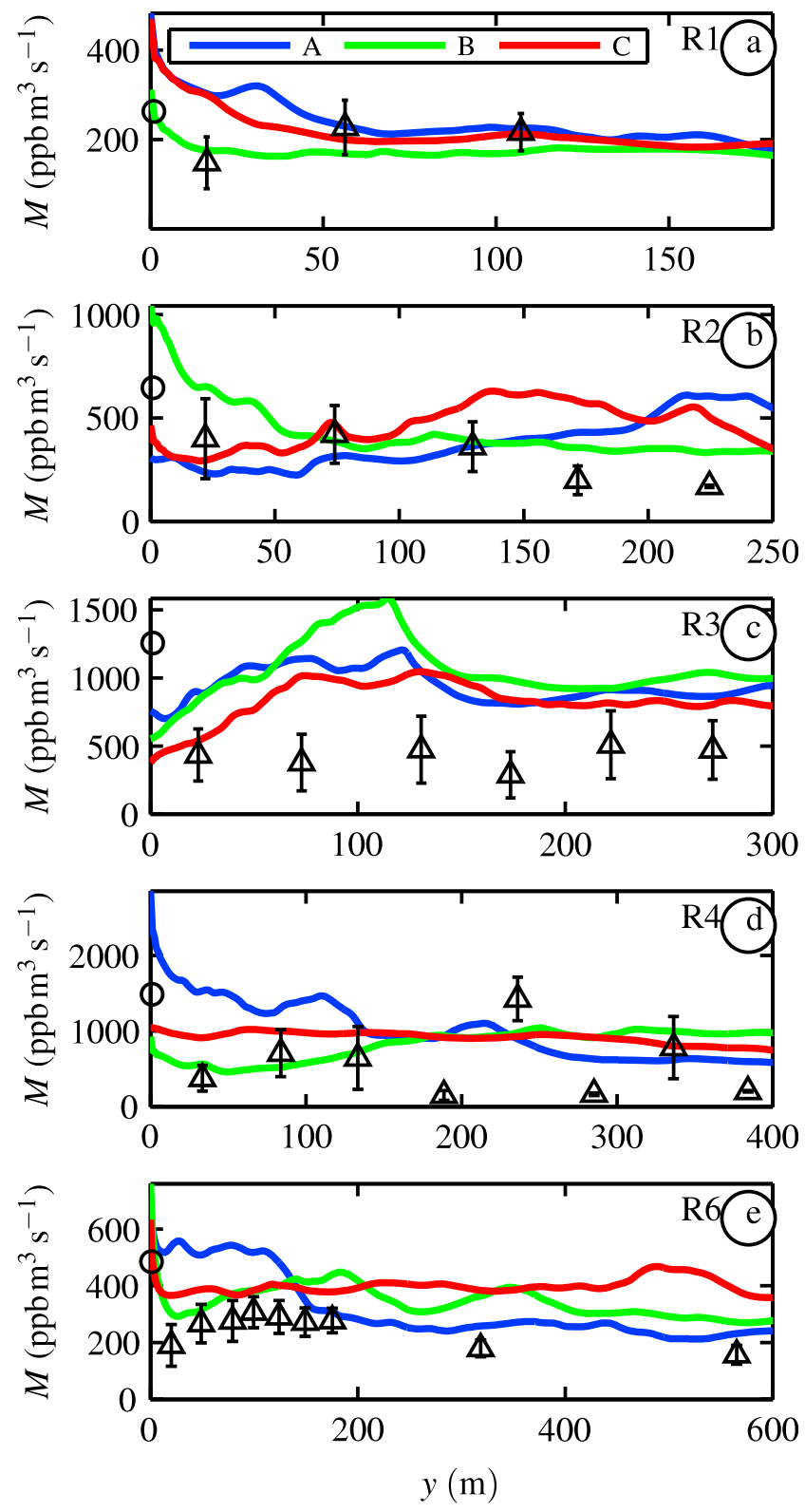

Figure 5. Modeled $M^{(\mathrm{A}, \mathrm{B}, \mathrm{C})}$ (colored curved) and observed $M^{\text {(obs) }}$ (open black triangles with error bars) alongshore tracer transport (2) versus $y$, for releases (a) R1, (b) R2, (c) R3, (d) R4, and (e) R6. The observed dye release rate is estimated by the open black circle at $y=0$.

always drove seaward until dye concentrations were not detectable. The model $x_{\text {out }}$ is taken at the seaward tracer boundary.

[26] Surf zone bulk cross-shore diffusivity $\kappa_{x x}$ is estimated using the surf zone-specific squared cross-shore length scale $\sigma_{\text {surf, }}^{2}$ a shoreline based second moment [Clark et al., 2010]

$$
\sigma_{\text {surf }}^{2}(y)=\frac{\int_{-L_{x}}^{x_{\mathrm{in}}} x^{2} D(x, y) d x}{\int_{-L_{x}}^{x_{\mathrm{in}}} D(x, y) d x},
$$

integrated from the seaward extent of the surf zone $x=-L_{x}$ (at the location of maximum $H_{\mathrm{s}}$ ) to $x=x_{\text {in }}$. The $H_{\mathrm{s}}$ were modeled with high skill (Part 1), thus modeled and observed $L_{x}$ are similar (12 m RMS difference). However, the $H_{\mathrm{s}}$ are observed at discrete locations (roughly $20 \mathrm{~m}$ apart) resulting in coarse $L_{x}$ resolution. For comparisons, the observed $L_{x}$ are used in (4) to estimate model and observed $\sigma_{\text {surf }}^{2}$. The shoreline based (i.e., without subtracting $\mu$ ) moment $\sigma_{\text {surf }}^{2}$ is appropriate for estimating $\kappa_{x x}$ near a boundary, assuming the alongshore plume axis is parallel to the shoreline, i.e., no large-scale cross-shore advection of the mean plume [Clark et al., 2010].

[27] For each release, a bulk $\kappa_{x x}$ is estimated from transects that are well contained in the surf zone, thus not effected by smaller diffusivities seaward of the surf zone. Transects are defined as well contained in the surf zone when $\mathcal{R}<0.55$, where $\mathcal{R}$ is the ratio of plume $\sigma_{\text {surf }}^{2}$ to the $\sigma_{\text {surf }}^{2}$ for a crossshore uniform tracer concentration [Clark et al., 2010]. For each release, the bulk $\kappa_{x x}$ is

$$
\sigma_{\text {surf }}^{2}=2 \kappa_{x x} t_{\mathrm{p}}+\beta
$$

where $\kappa_{x x}$ and $\beta$ are fit constants. The plume alongshore advection time

$$
t_{\mathrm{p}}=\bar{V}^{-1} y,
$$

is the approximate plume age at a downstream location $y$, where the overbar represents a surf zone average (cross-shore average over the surf zone). The observed $\bar{V}$ are estimated using the cross-shore array of current meters [Clark et al., 2010], and the model $\bar{V}$ is averaged over the surf zone $\left(-L_{x}<x<0\right)$ and the alongshore region between the release location $y=0$ and the farthest downstream location where $\kappa_{x x}$ is estimated $(\mathcal{R}<0.55)$. The Fickian solutions used to derive (5) assume constant depth, however numerical solutions to the depth varying case have similar surface tracer moments (i.e., (3) and (4)) and the resulting $\kappa_{x x}$ are within $10 \%$ of the constant depth estimates [Clark et al., 2010]. The observed R1 plume differs from the other releases because the plume moved seaward and did not interact strongly with the shoreline (Figure 4a) [Clark et al., 2010]. Thus, the observed R1 $\kappa_{\frac{x x}{2 x}}^{\text {(obs) }}$ is estimated from the squared cross-shore length scale $\sigma^{2}$, where the cross-shore advection is removed (for details see Clark et al. [2010]).

\subsection{Surface Center of Mass $\mu$}

[28] For all releases, the observed $\mu^{(\text {obs })}$ and modeled $\mu^{(\mathrm{A}, \mathrm{B}, \mathrm{C})}$ generally move seaward at an approximately constant rate with increasing downstream distance $y$, for $y<300 \mathrm{~m}$ (Figure 6). The downstream evolution of $\mu^{\text {(obs) }}$ and $\mu^{(\mathrm{A}, \mathrm{B}, \mathrm{C})}$ are similar for R2, R3, and R4 (Figures 6b-6d). The R1 $\mu^{(\mathrm{obs})}$ and $\mu^{(\mathrm{A}, \mathrm{B}, \mathrm{C})}$ are similar at the closest transect to the source (Figure 6a), but $\mu^{\text {(obs) }}$ magnitudes are slightly larger than $\mu^{(\mathrm{A}, \mathrm{B}, \mathrm{C})}$ for the two farthest downstream transects, consistent with seaward advection of the observed R1 plume (Figure 4a), possibly by unresolved local bathymetric variation [Clark et al., 2010]. The R6 modeled $\mu^{(\mathrm{C})}$ closely match the $\mu^{(\mathrm{obs})}$, but $\mu^{(\mathrm{A})}$ and $\mu^{(\mathrm{B})}$ magnitudes are generally larger than the $\mu^{\text {(obs) }}$, with more alongshore variation in $\mu^{(\mathrm{A})}$ and $\mu^{(\mathrm{B})}$ than $\mu^{\text {(obs) }}$. The disparity corresponds with small patches of $D^{(\mathrm{A})}$ $(x<-88 \mathrm{~m}$, Figure $2 \mathrm{f})$ and $D^{(\mathrm{B})}$ seaward of the surf zone. In R4 and R6 where the plume was measured farther downstream $(y>300 \mathrm{~m})$, the rate that $\mu$ moves away from the shoreline 

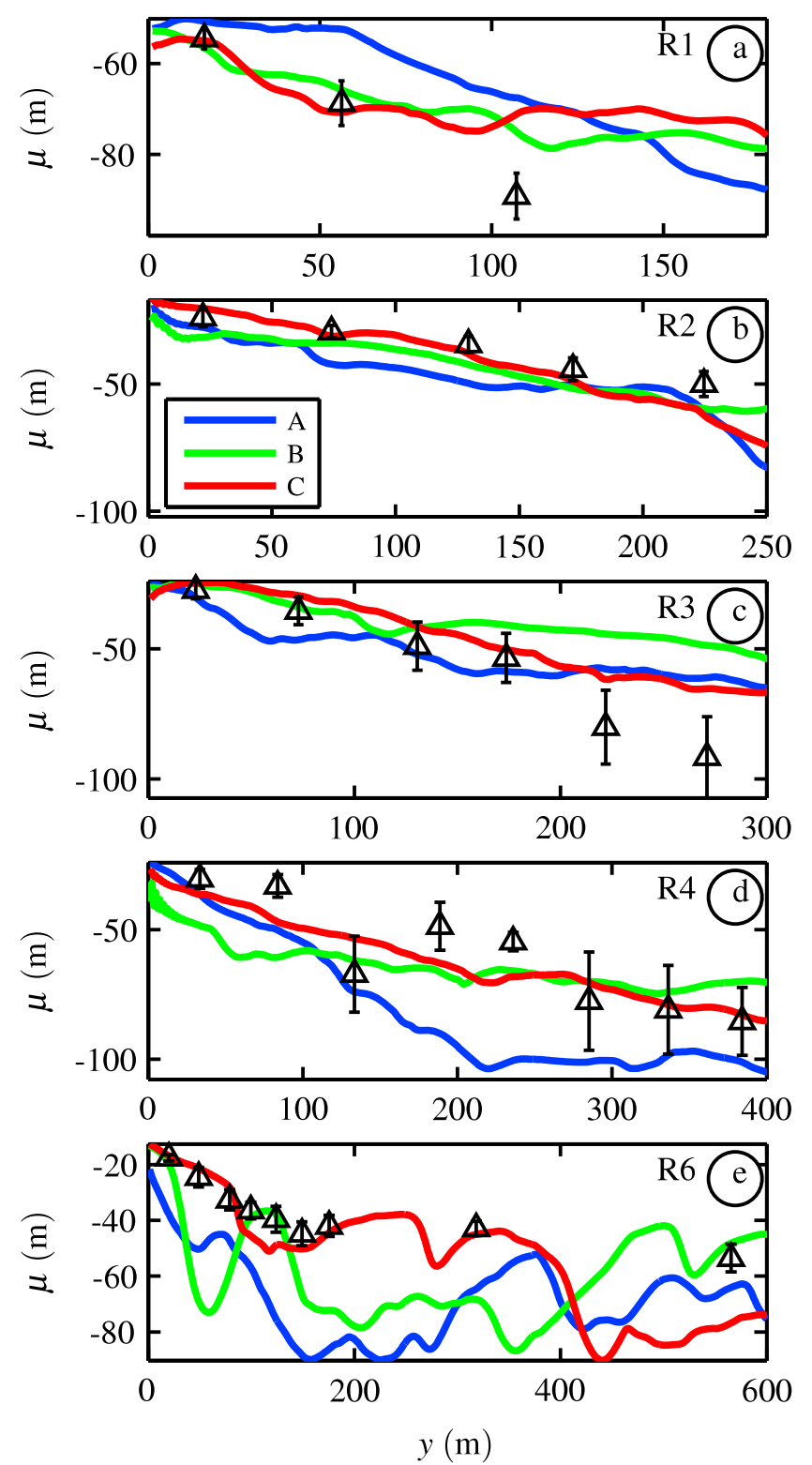

Figure 6. Modeled (colored) and observed (black triangles with error bars) surface center of mass $\mu$ versus $y$ for releases (a) R1, (b) R2, (c) R3, (d) R4, and (e) R6. The mean model skill over all releases is 0.88 .

decreases (Figures 6d and 6e) presumably owing to weaker mixing seaward of the surf zone. The $\mu^{(\mathrm{A}, \mathrm{B}, \mathrm{C})}$ skill, $1-$ $\left\langle\left(\mu^{(\mathrm{obs})}(y)-\mu^{(\mathrm{A}, \mathrm{B}, \mathrm{C})}(y)\right)^{2}\right\rangle_{y} /\left\langle\mu^{2(\mathrm{obs})}(y)\right\rangle_{y}$, is estimated for each tracer and release. The mean $\mu^{(\mathrm{A}, \mathrm{B}, \mathrm{C})}$ skill over all releases and tracers is 0.88 indicating good model-data agreement.

\subsection{Cross-Shore Dispersion and $\kappa_{x x}$}

[29] The model $\sigma_{\text {surf }}^{2(\mathrm{~B}, \mathrm{C})}$ and observed $\sigma_{\text {surf }}^{2(\mathrm{obs})}$ plume squared cross-shore length scales (4) increase with increasing plume alongshore advection time $t_{\mathrm{p}}(6)$, and are qualitatively well modeled for R2, R3, R4, and R6 (Figures 7b-7e). The initial increase in $\sigma_{\text {surf }}^{2(A, C)}$ and $\sigma_{\text {surf }}^{2(\text { obs })}$ is roughly linear in $t_{\mathrm{p}}$ (Figure 7) consistent with Brownian diffusion regimes. The $\sigma_{\text {surf }}^{2(\mathrm{~A}, \mathrm{~B}, \mathrm{C})}$ skill, $1-\left\langle\left(\sigma_{\text {surf }}^{2(\mathrm{obs})}\left(t_{\mathrm{p}}\right)-\sigma_{\text {surf }}^{2(\mathrm{~A}, \mathrm{~B}, \mathrm{C})}\left(t_{\mathrm{p}}\right)\right)^{2}\right\rangle_{t_{\mathrm{p}}} /$
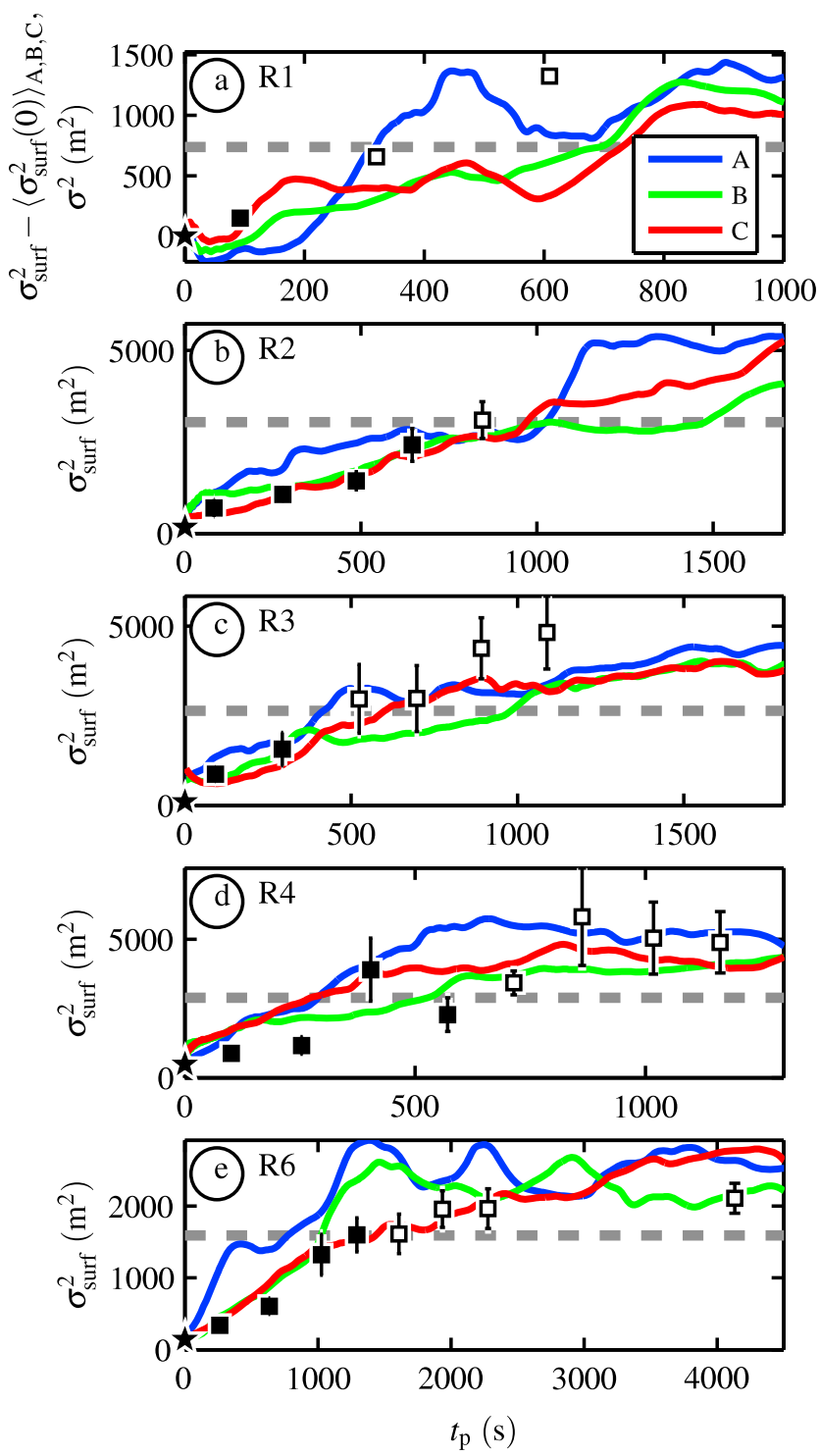

Figure 7. Modeled (color curves) and observed (black or white squares with error bars) squared cross-shore length

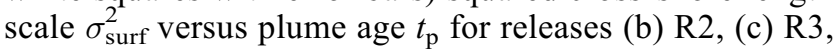
(d) R4, and (e) R6 and (a) $\sigma_{\text {surf }}^{2(\mathrm{~A}, \mathrm{~B}, \mathrm{C})}\left(t_{\mathrm{p}}\right)-\left\langle\sigma_{\text {surf }}^{2(\mathrm{~A}, \mathrm{~B}, \mathrm{C})}\left(t_{\mathrm{p}}=\right.\right.$ $0)\rangle_{\mathrm{A}, \mathrm{B}, \mathrm{C}}$ (modeled) and $\sigma^{2}$ (observed) for release R1. Tracer profiles that are well contained in the surf zone, where $\kappa_{x x}$ is fit, are indicated by black squares (observed) or the region below the dashed gray line (model) with $\mathcal{R}<0.55$. The $\sigma_{\text {surf }}^{2 \text { (obs) }}$ initial conditions (assuming a $\delta$ function at $t_{\mathrm{p}}=0$ ) are indicated by the black stars. The mean $\sigma_{\text {surf }}^{2}\left(t_{\mathrm{p}}\right)$ skill over releases $\mathrm{R} 2, \mathrm{R} 3, \mathrm{R} 4$, and R6 is 0.92 .

Table 3. Mean Model $\left\langle\kappa_{x x}\right\rangle_{\mathrm{A}, \mathrm{B}, \mathrm{C}}$ Derived From $\sigma_{\text {surf }}^{2}$ Versus $t_{\mathrm{p}}$ (Figure 8)

\begin{tabular}{cc}
\hline Release & $\left\langle\kappa_{x x}\right\rangle_{\mathrm{A}, \mathrm{B}, \mathrm{C}}$ \\
\hline R1 & $0.73 \pm 0.29$ \\
R2 & $1.02 \pm 0.17$ \\
R3 & $1.49 \pm 0.30$ \\
R4 & $2.83 \pm 0.76$ \\
R6 & $0.67 \pm 0.07$ \\
\hline
\end{tabular}




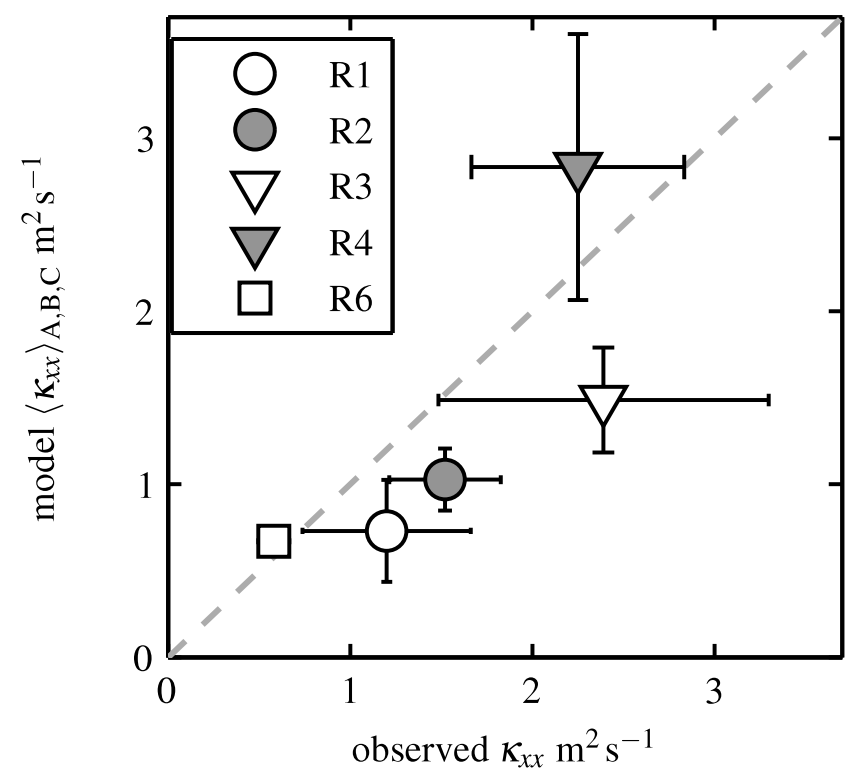

Figure 8. Mean modeled $\left\langle\kappa_{x x}\right\rangle_{\mathrm{A}, \mathrm{B}, \mathrm{C}}$ versus observed $\kappa_{x x}^{(\mathrm{obs})}$, with a dashed line indicating perfect agreement. The $\kappa_{x x}^{\text {(obs) }}$ and $\left\langle\kappa_{x x}\right\rangle_{\mathrm{A}, \mathrm{B}, \mathrm{C}}$ error bars are estimated from the $\sigma_{\text {surf }}^{2}$ versus $t_{\mathrm{p}}$ fit slope errors as detailed by Clark et al. [2010]. The skill is 0.40 .

$\left\langle\left(\sigma_{\text {surf }}^{2(\text { obs })}\left(t_{\mathrm{p}}\right)\right)^{2}\right\rangle_{t_{\mathrm{p}}}$, averaged over releases R2, R3, R4, and $\mathrm{R} 6$ is 0.92 . For the purpose of comparison, the R1 $\sigma_{\text {surf }}^{2 \text { (obs) }}\left(t_{\mathrm{p}}\right)$ is compared with the modeled $\sigma_{\text {surf }}^{2(\mathrm{~A}, \mathrm{~B}, \mathrm{C})}\left(t_{\mathrm{p}}\right)-\left\langle\sigma_{\text {surf }}^{2(\mathrm{~A}, \mathrm{C})}\left(t_{\mathrm{p}}=\right.\right.$ $0)\rangle_{\mathrm{A}, \mathrm{B}, \mathrm{C}}$ (Figure 7a). The R1 modeled and observed squared cross-shore length scales evolve similarly (Figure 7a), but this comparison is qualitative and skill is not estimated.

[30] Mean modeled cross-shore surf zone diffusivities $\left\langle\kappa_{x x}\right\rangle_{\mathrm{A}, \mathrm{B}, \mathrm{C}}$ (averaged across tracers A, B, and C) are estimated by least squares fits (5) where the tracer plumes are surf zone contained $(\mathcal{R}<0.55$, below the dashed gray lines in Figure 7 ). The R1 $\kappa_{x x}^{(\mathrm{obs})}$ is a special case discussed by Clark et al. [2010]. Linear fits to $\sigma_{\text {surf }}^{2(\mathrm{~A}, \mathrm{C})}$ versus $t_{\mathrm{p}}$ have high $r^{2}$ values, with a mean $r^{2}=0.87$. The $\left\langle\kappa_{x x}\right\rangle_{\mathrm{A}, \mathrm{B}, \mathrm{C}}$ errors are derived in the same manner as the observations [Clark et al., 2010], and include uncertainties in $\sigma_{\text {surf }}^{2(\mathrm{~A}, \mathrm{~B}, \mathrm{C})}$ and variations between $\sigma_{\text {surf }}^{2(\mathrm{~A}, \mathrm{~B}, \mathrm{C})}$ best fit slopes [Wunsch, 1996]. The $\left\langle\kappa_{x x}\right\rangle_{\mathrm{A}, \mathrm{B}, \mathrm{C}}$ range from 0.67 to $2.83 \mathrm{~m} \mathrm{~s}^{-1}$ (Table 3).

[31] Model $\left\langle\kappa_{x x}\right\rangle_{\mathrm{A}, \mathrm{B}, \mathrm{C}}$ and observed $\kappa_{x x}^{(\mathrm{obs})}$ are similar (Figure 8), with correlation $r^{2}=0.72$. The skill, $1-\left\langle\left(\kappa_{x x}^{(\mathrm{obs})}-\right.\right.$ $\left.\left.\left\langle\kappa_{x x}\right\rangle_{\mathrm{A}, \mathrm{B}, \mathrm{C}}\right)^{2}\right\rangle_{\mathrm{R} 1-\mathrm{R} 6}\left\langle\left(\kappa_{x x}^{\text {(obs) }}\right)^{2}\right\rangle_{\mathrm{R} 1-\mathrm{R} 6}$, is 0.40 . Model and observed cross-shore dispersion $\kappa_{x x}$ are qualitatively similar for the given bathymetries and incident wave fields.

\section{Discussion}

\subsection{Model-Data Comparison}

\subsubsection{Mean Plume Concentration $D$ and Alongshore Transport $M$}

[32] The magnitude and cross-shore structure of tracer concentration $D^{(\mathrm{A}, \mathrm{B}, \mathrm{C})}$ is more difficult to model than crossshore integrated, normalized moments ( $\mu$ and $\sigma_{\text {surf }}^{2}$ ), because $D^{(\mathrm{A}, \mathrm{B}, \mathrm{C})}$ depends on the details of $V(x)$, eddy stirring, and the input tracer flux. Model and observed $D^{(\mathrm{A})}$ and $D^{(\mathrm{obs})}$ are similar with good skill (0.5-0.73) for releases R3, R4, and R6
(Figures $4 \mathrm{c}-4 \mathrm{e}$ ), where the waves, $V(x)$, and eddy velocities were also well modeled (Part 1). However, other releases have significant deviations in plume location (R1, Figure 4a) or tracer magnitude (R2, Figure 4b) leading to low (negative) $D^{(\mathrm{A})}$ skill. The difference in R1 cross-shore plume location likely results from cross-shore advection of the mean $D^{(\mathrm{obs})}$ plume (i.e., the along-plume axis is not parallel to shore). The R2 $D^{(\mathrm{A})}$ are reasonably matched in the outer surf zone $(x<-60 \mathrm{~m}$, Figure $4 \mathrm{~b})$, but $D^{(\mathrm{A})}$ magnitudes are often 2 5 times greater than $D^{(\mathrm{obs})}$ near the shoreline, contrasting with the good agreement between R2 $M^{(\mathrm{A}, \mathrm{B}, \mathrm{C})}$ and $M^{(\mathrm{obs})}$ tracer transports (Figure 5b). Near the shoreline, the R2 model $V \approx$ $0.05 \mathrm{~m} \mathrm{~s}^{-1}$ substantially underpredicts the observed $V \approx$ $0.3 \mathrm{~m} \mathrm{~s}^{-1}$ (Part 1, Figure 6), but combined with the overpredicted $D^{(\mathrm{A})}$ (Figure $4 \mathrm{~b}$ ), results in good $M$ model-data agreement (Figure 5b).

\subsubsection{Cross-Shore Moments $\mu$ and $\sigma_{\text {surf }}^{2}$}

\section{and Diffusivity $\kappa_{x x}$}

[33] Although $D^{(\mathrm{A}, \mathrm{B}, \mathrm{C})}$ skill is variable and sometime negative, the normalized cross-shore integrated moments $\mu^{(\mathrm{A}, \mathrm{B}, \mathrm{C})}(3)$ and $\sigma_{\text {surf }}^{2(\mathrm{~A}, \mathrm{~B}, \mathrm{C})}(4)$, representing cross-shore plume structure, have high mean skill ( 0.88 and 0.92 , respectively). For example, despite low $D^{(\mathrm{A}, \mathrm{B}, \mathrm{C})}$ skill, R2 has high $\mu^{(\mathrm{A}, \mathrm{B}, \mathrm{C})}$ skill (Figure $6 \mathrm{~b}$ ) and the best agreement (highest $\sigma_{\text {surf }}^{2(\mathrm{~B}, \mathrm{C})}$ skill) with the observed cross-shore dispersion (Figure $7 b$ ). This is in part due to scaling the model and observations with $t_{\mathrm{p}}$ which reduces the sensitivity to $\mathrm{R} 2 V(x)$ model errors. Thus cross-shore diffusivities $\kappa_{x x}$ may still be accurately modeled when $V(x)$ and $D^{(\mathrm{A}, \mathrm{B}, \mathrm{C})}$ are not.

[34] Drifter observations indicate ballistic dispersion $\left(\sigma^{2} \propto\right.$ $t^{2}$ ) for times $\lesssim 50 \mathrm{~s}$ and Brownian dispersion at longer times [Spydell et al., 2009]. Tracer observations were generally at downstream distances corresponding to $t_{\mathrm{p}}>100 \mathrm{~s}$ [Clark et al., 2010], and the observed and the modeled $\sigma_{\text {surf }}^{2}$ are consistent with Brownian diffusion $\left(\sigma^{2} \propto t\right.$, Figure 7). At short times (where there are no observations), a ballistic dispersion regime is not apparent in the model $\sigma_{\text {surf }}^{2(\mathrm{~A}, \mathrm{~B}, \mathrm{C})}$, potentially because of a mix of background diffusivity, bore mixing, and eddy stirring which all have different time scales.

[35] Model $\left\langle\kappa_{x x}\right\rangle_{\mathrm{A}, \mathrm{B}, \mathrm{C}}$ and observed $\kappa_{x x}^{(\mathrm{obs})}$ are similar with correlation $r^{2}=0.72$ and moderate 0.40 skill (Figure 8 ). Thus, given only the bathymetry and incident wave field, the coupled Boussinesq-tracer model qualitatively reproduces the observed cross-shore absolute tracer dispersion and suggests that the model can be used to study the mechanisms of surf zone tracer dispersion.

\subsubsection{R6 Dispersion, Seaward of the Surf Zone}

[36] The R6 $\mu^{(\mathrm{C})}$ closely matches $\mu^{(\mathrm{obs})}$, but $\mu^{(\mathrm{A})}$ and $\mu^{(\mathrm{B})}$ are farther seaward, resulting in the lowest $\mu^{(\mathrm{A}, \mathrm{B}, \mathrm{C})}$ mean skill $(0.68)$ of all releases. Despite the highest $D^{(\mathrm{A}, \mathrm{B}, \mathrm{C})}$ skill (Table 2), low concentrations of $D^{(\mathrm{A})}$ and $D^{(\mathrm{B})}$ extend much farther seaward than the $D^{(\mathrm{obs})}$ (see Figure $4 \mathrm{e}$ for $D^{(\mathrm{A})}$ ), thus increasing $\mu^{(\mathrm{A})}$ and $\mu^{(\mathrm{B})}$ magnitudes. This may indicate model mixing rates seaward of the surf zone are larger, or have different structure, than observed. Seaward of the surf zone, vertical tracer structure, not accounted for here, may also become important [e.g., Kim and Lynett, 2010].

\subsubsection{Potential Sources of Error}

[37] The variation between modeled individual tracer $(\mathrm{A}, \mathrm{B}, \mathrm{C})$ statistics (e.g., $\sigma_{\text {surf }}^{2(\mathrm{~A}, \mathrm{~B}, \mathrm{C})}$, Figure 7 ) is due to two factors. First, small alongshore variations in the surf zone 


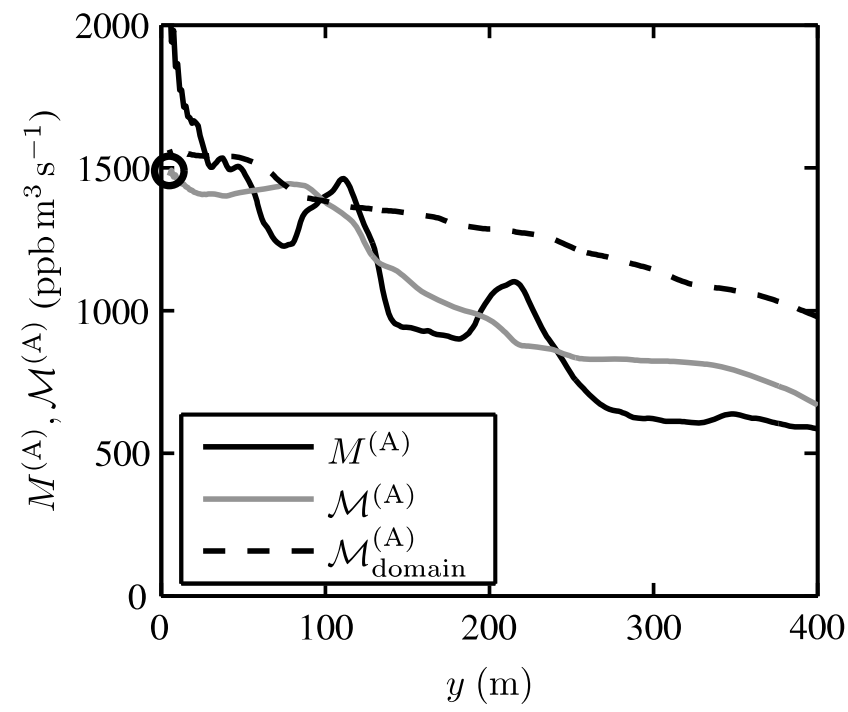

Figure 9. Alongshore tracer transport estimates $M^{(\mathrm{A})}(2)$, $\mathcal{M}^{(\mathrm{A})}(7)$, and $\mathcal{M}_{\text {domain }}^{(\mathrm{A})}$ (see legend) versus $y$ for $\mathrm{R} 4$. Note that $\mathcal{M}_{\text {domain }}^{(\mathrm{A})}$ is defined similar to $\mathcal{M}^{(\mathrm{A})}$ but is integrated over the entire cross-shore tracer domain. Mean and eddy fluxes are included in both $\mathcal{M}^{(\mathrm{A})}$ and $\mathcal{M}_{\text {domain. }}^{(\mathrm{A})}$. The observed dye release rate is given by the open black circle at $y=0 \mathrm{~m}$.

eddy field (e.g., Part 1, Figures 14 and 15) result in each tracer experiencing slightly different stirring statistics. Second, the velocity field stirring the tracer has a red spectrum (Part 1, Figure 13) that is intrinsic (as in 2D turbulence) and does not depend on the model wave maker. Thus, averaging for $8000 \mathrm{~s}$ may not be sufficient to completely converge tracer statistics from the three release locations. Significantly longer model simulations allow for more lower-frequency energy, possibly negating any reduction in uncertainty provided by longer averages. Statistical stability in $\left\langle\kappa_{x x}\right\rangle_{\mathrm{A}, \mathrm{B}, \mathrm{C}}$ is increased by averaging over the 3 alongshore separated tracers.

[38] The observed $\kappa_{x x}^{\text {(obs) }}$ estimates assume $\sigma_{\text {surf }}^{2(\text { obs })}\left(t_{\mathrm{p}}=0\right)=$ $x_{\mathrm{rl}}^{2}$ (tracer $\delta$ function at the release location). However, the model $\sigma_{\text {surf }}^{2(\mathrm{~B}, \mathrm{C})}\left(t_{\mathrm{p}}=0\right)$ for R2, R3, and R4 are larger (by 153$724 \mathrm{~m}^{2}$ ) than the assumed $x_{\mathrm{rl}}^{2}$ value for the observations (Figures $7 \mathrm{~b}-7 \mathrm{~d})$. The elevated model $\sigma_{\text {surf }}^{2(\mathrm{~A}, \mathrm{~B}, \mathrm{C})}$ relative to $x_{\mathrm{rl}}^{2}$ is due to intermittent model tracer recirculation upstream of the tracer source (e.g., Figure 2a), and consistent with visual observations. Additional model experiments with nonbreaking waves on a steady current demonstrate that cross-shore tracer dispersion due to orbital wave motions is weak and contributes only a small fraction of the model $\sigma_{\text {surf }}^{2(\mathrm{~A}, \mathrm{C})}$ near $y=0 \mathrm{~m}$. The assumed $\sigma_{\text {surf }}^{2(\mathrm{obs})}\left(t_{\mathrm{p}}=0\right)=x_{\mathrm{rl}}^{2}$ likely underestimates the actual value, and the observed fit slopes (5) and $\kappa_{x x}^{(\mathrm{obs})}$ may be slightly overestimated.

\subsection{Alongshore Tracer Transport: Eddy Fluxes and Cross-Shore Integration Limits}

[39] For equilibrated conditions ( $t>6000 \mathrm{~s}$, Figure 3 ) and conserved tracer, the time averaged alongshore tracer transport is expected to be constant downstream of the source. However, the model and observed $M(2)$ are not conserved, do not match the input flux, and vary downstream by up to $50 \%$ (Figure 5). Model and observed tracer transports $M$ are both estimated using time-averaged $D$ and $V(2)$, excluding alongshore eddy fluxes, and neglect the regions onshore of $x_{\text {in }}$ and offshore of $x_{\mathrm{F} 7}$. The time-averaged total alongshore tracer transport $\mathcal{M}(y)$ is estimated with

$$
\mathcal{M}(y)=\int_{x_{\mathrm{F} 7}}^{x_{\mathrm{in}}}\langle[h(x)+\eta(x, y, t)] v(x, y, t) d(x, y, t)\rangle_{t} d x,
$$

where $v$ and $d$ are the instantaneous model alongshore velocity and tracer concentration, respectively, and the timeaveraged $\langle[h+\eta] v d\rangle_{t}$ includes both mean and eddy alongshore tracer fluxes. The $x_{\text {in }}<x<x_{\mathrm{F} 7}$ integral limits are used for comparison with $M^{(\mathrm{A}, \mathrm{B}, \mathrm{C})}(2)$. The $\mathrm{R} 4 \mathcal{M}^{(\mathrm{A})}$, representative of other tracers and releases, matches the input flux at $y=$ 0 and varies less downstream than $M^{(\mathrm{A})}$ (Figure 9). The $\mathcal{M}^{(\mathrm{A})}$ and $M^{(\mathrm{A})}$ have roughly similar magnitudes, indicating small alongshore eddy fluxes, consistent with the assumptions used to derive $\kappa_{x x}(5)$.

[40] A domain integrated total transport estimate $\mathcal{M}_{\text {domain }}^{(\mathrm{A})}$ is defined similarly to (7) but integrated over the entire crossshore tracer domain (Figure 1). The $\mathcal{M}_{\text {domain }}^{(\mathrm{A})}$ decreases less downstream than $M^{(\mathrm{A})}$ and $\mathcal{M}^{(\mathrm{A})}$ (Figure 9). The $\mathcal{M}^{(\mathrm{A})}$ are initially $(y<100 \mathrm{~m})$ smaller than $\mathcal{M}_{\text {domain }}^{(\mathrm{A})}$ because $\mathcal{M}^{(\mathrm{A})}$ excludes tracer shoreward of $x_{\mathrm{in}}$. The $\mathcal{M}^{(\mathrm{A})}$ are also smaller farther downstream $(y>200 \mathrm{~m})$ because tracer transport seaward of $x_{\mathrm{F} 7}$ is excluded. The downstream decrease in $\mathcal{M}_{\text {domain }}^{\text {A) }}$ is due to tracer losses at the offshore boundary, indicating that a larger cross-shore domain, in addition to incorporating the effects of vertical variation of tracer and currents and stratification, are needed to study tracer evolution seaward of the surf zone.

\subsection{Simple Fickian Equation Comparison: Tracer Maxima}

[41] Cross-shore diffusivity $\kappa_{x x}$ is estimated here and by Clark et al. [2010] using a simple Fickian solution, where the tracer cross-shore maxima decrease downstream as $D_{\max } \sim t_{\mathrm{p}}^{-1 / 2}$ [Clark et al., 2010]. The individual $D_{\max }^{(\mathrm{A}, \mathrm{B}, \mathrm{C})}$ model tracers are similar, and the mean $\left[\langle D\rangle_{\mathrm{A}, \mathrm{B}, \mathrm{C}}\right]_{\max }$ over tracers $\mathrm{A}, \mathrm{B}$, and $\mathrm{C}$ is compared with the expected $t_{\mathrm{p}}^{-1 / 2}$ dependence over the surf zone contained region where $\kappa_{x x}$ is estimated.

[42] The R1, R4, and R6 [ $\left.\langle D\rangle_{\mathrm{A}, \mathrm{B}, \mathrm{C}}\right]_{\max }$ decrease similarly to $t_{\mathrm{p}}^{-1 / 2}$ (Figure 10 ). The $\mathrm{R} 2$ and $\mathrm{R} 3\left[\langle D\rangle_{\mathrm{A}, \mathrm{B}, \mathrm{C}}\right]_{\max }$ initially $\left(t_{\mathrm{p}}<200 \mathrm{~s}\right)$ decrease similarly to $t_{\mathrm{p}}^{-1 / 2}$, but decrease more rapidly with $t_{\mathrm{p}}>200 \mathrm{~s}$ (Figure 10 ), possibly because tracer is leaking into deeper water seaward of the surf zone. Linear regressions of the form $\left[\langle D\rangle_{\mathrm{A}, \mathrm{B}, \mathrm{C}}\right]_{\max }=A t^{-\gamma}$, with $A$ and $\gamma$ fit constants, yield $\gamma$ slightly greater than 0.5 . The similarity between $\left[\langle D\rangle_{\mathrm{A}, \mathrm{B}, \mathrm{C}}\right]_{\max }$ and $t_{\mathrm{p}}^{-1 / 2}$ indicates that (5) is appropriate for estimating $\kappa_{x x}$, and that the modeled absolute diffusion is generally well represented by a simple Fickian equation, when the tracer is well contained within the surf zone. Diffusivities estimated from $\left[\langle D\rangle_{\mathrm{A}, \mathrm{B}, \mathrm{C}}\right]_{\max }$ versus $t_{\mathrm{p}}$ (not shown) are similar to those estimated from $\left.\sigma_{\text {surf }}^{2(\mathrm{~A}, \mathrm{C})}\right)^{\mathrm{p}}$, but are much noisier and include uncertainties in the absolute tracer concentration.

\subsection{Tracer Dispersion Induced by Breaking Wave $\kappa_{\mathrm{br}}$}

[43] For time-averaged breaking wave (bore) induced diffusion, scalings similar to $\kappa_{x x} \propto H_{\mathrm{s}}^{2} T_{\mathrm{m}}^{-1}$, were suggested by several previous studies [Harris et al., 1963; Inman et al., 1971; Clarke et al., 2007; Feddersen, 2007; Henderson, 2007], but had lower skill (0.32) than alternate scalings 


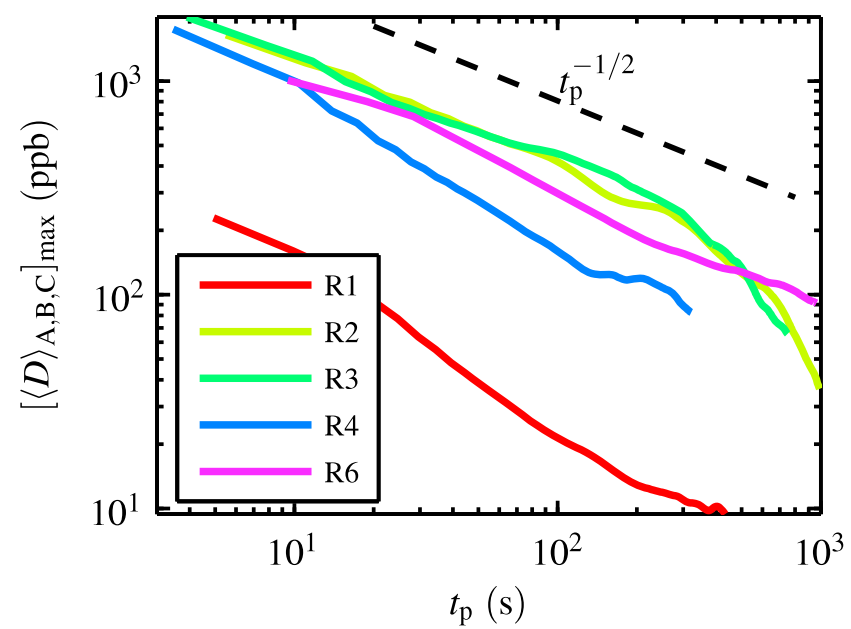

Figure 10. Mean (over tracers A, B, and C) cross-shore tracer maxima $\left[\langle D\rangle_{\mathrm{A}, \mathrm{B}, \mathrm{C}}\right]_{\max }$ versus plume age $t_{\mathrm{p}}$, for the downstream region where tracer is well contained within the surf zone (i.e., the region where $\kappa_{x x}$ is estimated). The $t_{\mathrm{p}}^{-1 / 2}$ slope based on Fickian diffusion is indicated by the dashed black line.

and best fit slope smaller than expected when applied to the HB06 observed $\kappa_{x x}$ [Clark et al., 2010]. The relative importance of simulated bore diffusion is investigated for the modeled HB06 tracer plumes.

[44] Tracer mixing by breaking waves is modeled with a breaking eddy diffusivity $\kappa_{\text {br }}$ (set equal to the local breaking eddy viscosity $\nu_{\mathrm{br}}$ ), which propagates with the front face of a breaking wave (bore) [Feddersen, 2007]. In the absence of other dispersion mechanisms, a tracer patch that is much wider than the cross-shore width of a bore (approximately the water depth) has a bulk cross-shore diffusivity given by the time-averaged breaking diffusivity $\left\langle\kappa_{\mathrm{br}}\right\rangle_{t}$ [Henderson, 2007].

[45] The R4 $\left\langle\kappa_{\mathrm{br}}\right\rangle_{t}$ increases from zero, far seaward of the surf zone, to a maxima near the outer surf zone $(x \approx-100 \mathrm{~m})$, and then decreases toward the shoreline (Figure 11). Although R4 has the largest breaking diffusivities of all

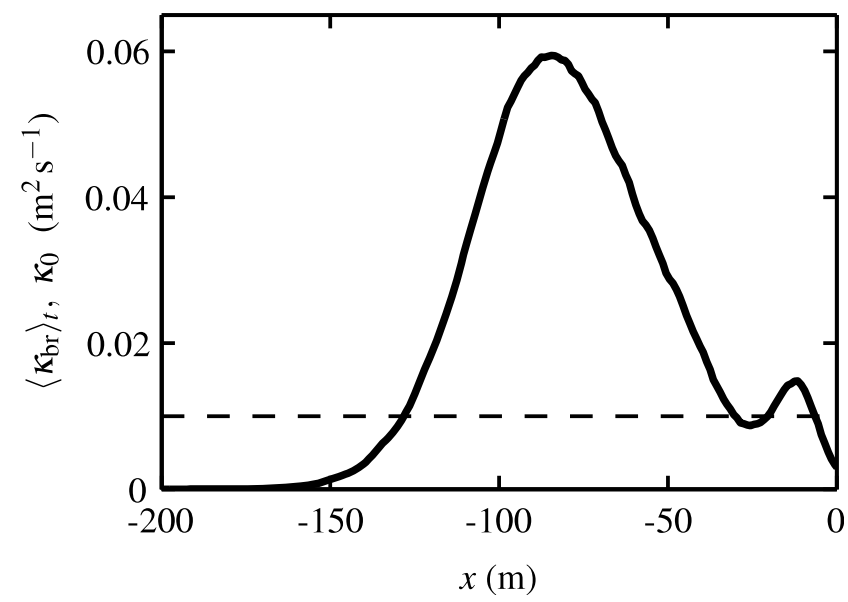

Figure 11. Time-averaged breaking wave diffusivity $\left\langle\kappa_{\mathrm{br}}\right\rangle_{t}$ (solid) and background diffusivity $\kappa_{0}=0.01 \mathrm{~m}^{2} \mathrm{~s}^{-1}$ (dashed) versus $x$ for R4.

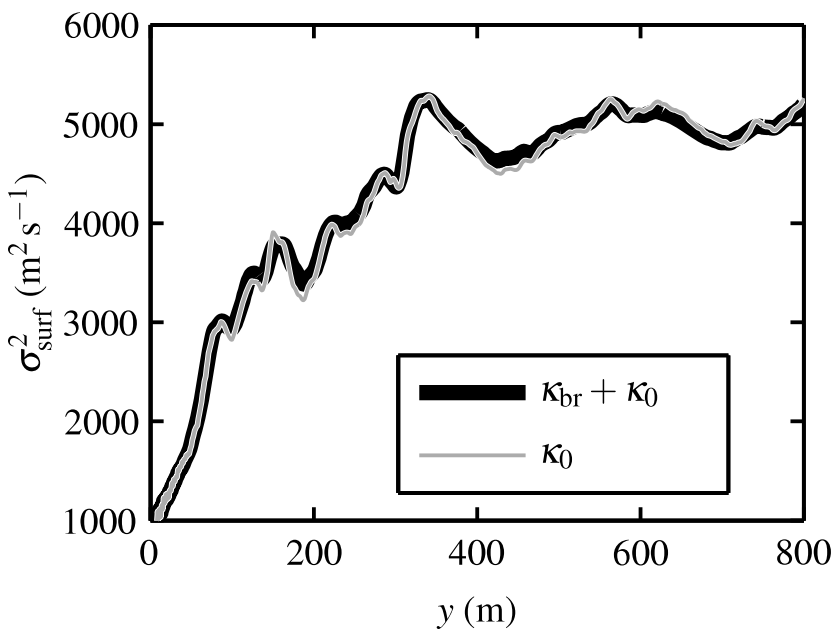

Figure 12. Model $\sigma_{\text {surf }}^{2}$ versus $y$ for two R4 tracers with identical release location: one with full breaking-induced diffusivity $\kappa_{\mathrm{br}}+\kappa_{0}$ (black) and another with background diffusivity $\kappa_{0}$ only (gray).

releases, the maximum $\left\langle\kappa_{\mathrm{br}}\right\rangle_{t}=0.06 \mathrm{~m}^{2} \mathrm{~s}^{-1}$ is much smaller than the $O(1)$ estimates for $\left\langle\kappa_{x x}\right\rangle_{\mathrm{A}, \mathrm{B}, \mathrm{C}}$ (Figure 8 and Table 3 ), suggesting the effect of bore mixing [Feddersen, 2007] on absolute averaged tracer properties is weak.

[46] The weak effect of breaking wave induced $\kappa_{\mathrm{br}}$ on cross-shore absolute dispersion is demonstrated by an additional R4 simulation with two tracers released at the same location, one with breaking and background diffusivities $\kappa_{\mathrm{br}}+\kappa_{0}$ and another with only background $\kappa_{0}$ applied to the tracer field. The R4 model $\sigma_{\text {surf }}^{2}$ with and without $\kappa_{\text {br }}$ are almost identical (Figure 12, other releases are similar), demonstrating that model bore-induced mixing is insignificant to bulk surf zone cross-shore dispersion for the obliquely incident, directionally spread wave conditions modeled here.

\subsection{Model Mixing Length $\kappa_{x x}$ Scalings}

[47] A mixing length scaling for the cross-shore diffusivity

$$
\kappa_{x x} \propto \overline{\mathcal{V}}_{\text {rot }}^{(\mathrm{IG})} L_{x}
$$

was compared with observed diffusivities, where $\overline{\mathcal{V}}_{\text {rot }}^{(\mathrm{IG})}$ is a surf zone-averaged infragravity horizontal rotational velocity (estimated following Lippmann et al. [1999] and discussed in Part 1) and $L_{x}$ is the surf zone width [Clark et al., 2010]. This scaling $(8)$ was correlated $\left(r^{2}=0.59\right)$ with observed $\kappa_{x x}^{(\mathrm{obs})}$, and suggested that stirring by infragravity (IG, $0.004<$ $f<0.03 \mathrm{~Hz}$ ) eddies (vortical motions) was a significant crossshore tracer dispersion mechanism. In addition, note that although $\kappa_{x x}^{\text {(obs) }}$ was also correlated with $\bar{V} L_{x}, \bar{V}$ appeared in the formulation for $\kappa_{x x}^{\text {(obs) }}$ and the correlation could be artificially high. The observed IG band rotational velocities $\mathcal{V}_{\text {rot }}^{(\mathrm{IG})}(x)$ were well reproduced by the model (see Part 1, Figure 14). Here, the mixing length scaling (8) is investigated for the modeled dispersion.

[48] The model $\overline{\mathcal{V}}_{\text {rot }}^{\text {(IG) }}$ are estimated by cross-shore averaging the model $\mathcal{V}_{\text {rot }}^{(\mathrm{IG})}(x)$ over the surf zone $\left(-L_{x}<x<0\right)$. Over the five releases, the model $\left\langle\kappa_{\mathrm{br}}\right\rangle_{\mathrm{A}, \mathrm{B}, \mathrm{C}}$ and $\overline{\mathcal{V}}_{\text {rot }}^{(\mathrm{IG})} L_{x}$ are related (Figure 13a), with a best fit slope of 0.1 . This slope is near the observed best fit slope of 0.2 suggesting that this 

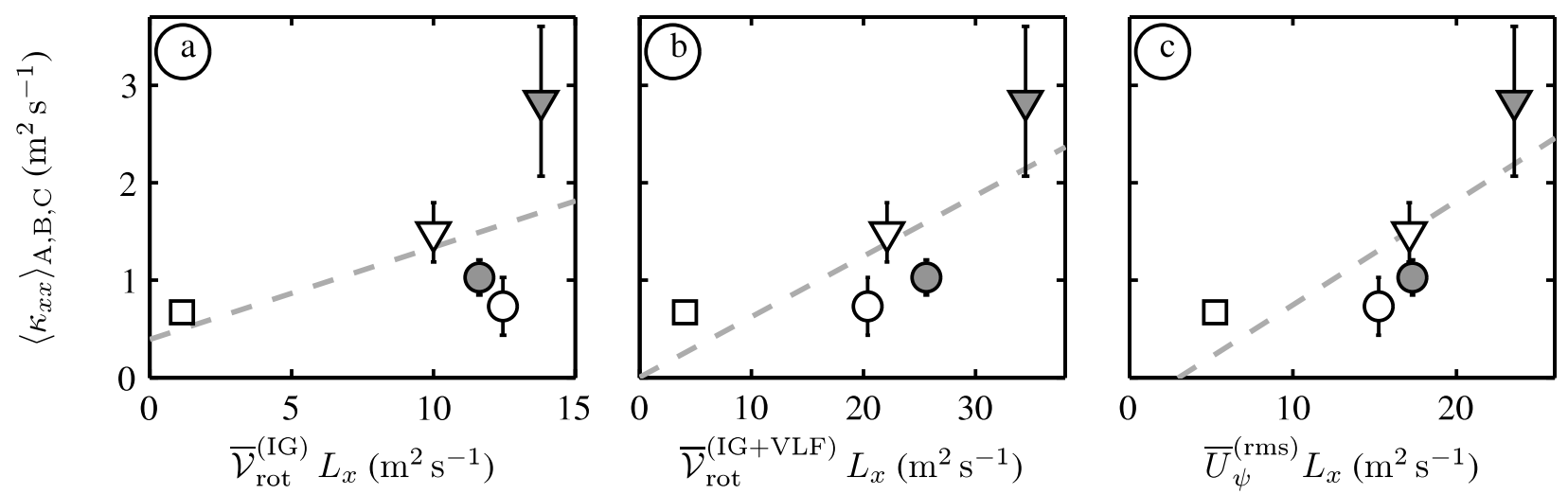

Figure 13. Model $\left\langle\kappa_{\text {br }}\right\rangle_{\text {A,B,C }}$ versus (a) $\overline{\mathcal{V}}_{\text {rot }}^{(\mathrm{IG})} L_{x}$, (b) $\overline{\mathcal{V}}_{\text {rot }}^{(\mathrm{IG}+\mathrm{VLF})} L_{x}$, and (c) $\bar{U}_{\psi}^{(\mathrm{RMS})} L_{x}$ scalings. The dashed gray line indicates linear fits to each scaling, and $r^{2}$ correlations are 0.29 (Figure 13a), 0.60 (Figure 13b), and 0.63 (Figure 13c).

scaling is also applicable in the model. However, the squared correlation $r^{2}=0.29$ is lower than observed $\left(r^{2}=0.59\right)$. The scaling is not expected to represent all the dispersive processes in the surf zone, and the diffusivity is expected to be nonzero (and positive) when $\overline{\mathcal{V}}_{\text {rot }}^{(\mathrm{IG})} L_{x}=0$. The positive best fit y intercept (Figure 13a) is roughly consistent with this expectation.

[49] Observed and modeled very low frequency (VLF, $f<$ $0.004 \mathrm{~Hz})$ contributions to the bulk rotational velocity estimate (Part 1, Figure 15), not considered by Clark et al. [2010], have similar magnitudes to those in the IG band (Part 1, Figure 14), and may represent a significant contribution to cross-shore mixing. A mixing length scaling $\kappa_{x x} \sim \overline{\mathcal{V}}_{\text {rot }}^{(\mathrm{IG}+\mathrm{VLF})}$ $L_{x}$ similar to (8), using a surf zone averaged horizontal rotational velocity $\mathcal{V}_{\text {rot }}^{(\mathrm{IG}+\mathrm{VLF})}$ integrated over both IG and VLF frequency bands $(0.001<f<0.03 \mathrm{~Hz})$, is tested for the model. The $\overline{\mathcal{V}}_{\text {rot }}^{\text {(IG }+\mathrm{VLF})} L_{x}$ scaling has a best fit slope of 0.06 , and a higher correlation $\left(r^{2}=0.60\right)$ with $\left\langle\kappa_{\text {br }}\right\rangle_{\mathrm{A}, \mathrm{B}, \mathrm{C}}$ (compare Figure 13b with Figure 13a), indicating that VLF motions are likely important to model cross-shore tracer dispersion in the surf zone. The best fit y intercept is near zero, similar to $\overline{\mathcal{V}}_{\text {rot }}^{\text {(IG) }} L_{x}$. The model rotational motions in the VLF frequency band are roughly twice the observed velocities, thus VLF motions may be more important to tracer dispersion in the model than in the field.

[50] Estimates of rotational velocities using a colocated pressure and velocity measurement [Lippmann et al., 1999] are useful for field applications, but involve assumptions about the low-frequency wave field. More accurate and complete rotational velocities are estimated by decomposing the model instantaneous velocity field into rotational $\boldsymbol{u}_{\psi}$ and irrotational $\boldsymbol{u}_{\phi}$ components [e.g., Spydell and Feddersen 2009; Part 1], where model vorticity comes entirely from the rotational $\boldsymbol{u}_{\psi}$. The majority of contributions to $\boldsymbol{u}_{\psi}$ are in the IG and VLF frequency bands (Part 1, Figure 13).

[51] While $\overline{\mathcal{V}}_{\text {rot }}^{(\mathrm{IG}+\mathrm{VLF})}$ combines both cross-shore and alongshore rotational motions, only the cross-shore component of the rotational velocity field (i.e., $u_{\psi}$ ) is expected to mediate cross-shore dispersion. A bulk cross-shore rotational velocity $\bar{U}_{\psi}^{\text {(RMS) }}$, estimated from the surf zone averaged RMS model cross-shore rotational velocities $u_{\psi}$, is applied to the scaling, i.e., $\kappa_{x x} \propto \bar{U}_{\psi}^{\text {(RMS) }} L_{x}$. This scaling has a squared correlation $r^{2}=0.63$ (Figure 13c), similar to the $\overline{\mathcal{V}}_{\text {rot }}^{(\mathrm{IG}+\mathrm{VLF})}$ squared correlation, and a best fit slope of 0.1 . The best fit $y$ intercept is negative, but close to zero. This scaling again suggests that VLF motions are an important factor in model dispersion.

[52] Unlike the diffusivity scalings and simple Fickian solutions (best fits to $\kappa_{x x}$ and $\sigma_{\text {surf }}^{2}$, respectively) the Boussinesq model is not tuned to match tracer statistics. Given the similarity between model and observed tracer dispersion, the model can give insight into tracer dispersion mechanisms and improve the skill and reliability (over a range of beach and wave conditions) of diffusivity scalings. Improved scalings may provide the rapid (albeit approximate) estimates needed to predict pollutant dispersal in an emergency.

\section{Summary}

[53] A time-dependent wave-resolving Boussinesq surf zone model funwaveC, coupled with a tracer advection diffusion equation, is used to simulate 5 tracer releases from the HB06 experiment. The model, using the observed bathymetry and incident wave spectra, reproduces the cross-shore evolution of significant wave height, mean alongshore currents, and low-frequency rotational motions, i.e., eddies (Part 1). Model tracer is transported by currents, stirred by eddies, and mixed with a breaking wave eddy diffusivity $\kappa_{\text {br }}$, and a small $\left(0.01 \mathrm{~m}^{2} \mathrm{~s}^{-1}\right)$ background diffusivity. Three noninteracting model tracers were released $250 \mathrm{~m}$ apart in the alongshore at the rates and cross-shore release locations of the observations.

[54] Similar to the observations, the continuously released model tracers form alongshore parallel plumes in the wavedriven alongshore current, with decreasing peak concentrations and increasing cross-shore widths with downstream distance from the source. Modeled $D^{(\mathrm{A}, \mathrm{B}, \mathrm{C})}$ and observed $D^{\text {(obs) }}$ mean tracer profiles are often shoreline attached (nearshoreline maxima). Three releases (R3, R4, and R6) have high $D$ skill $(0.5-0.73)$ with well matched plumes. Two releases (R1, R2) have negative skill, associated with a mismatch in plume cross-shore location (R1), or differences in the modeled and observed mean alongshore current near the shoreline (R2).

[55] The modeled alongshore tracer transport $M$ agrees with the data for most releases, but is overestimated for R3. 
Small tracer losses at the seaward model boundary do not effect surf zone dispersion results, but indicate a much larger cross-shore domain would be required to examine processes seaward of the surf zone. Alongshore tracer eddy fluxes are small, and in agreement with neglecting alongshore tracer dispersion in cross-shore diffusivity estimates.

[56] The observed and modeled cross-shore integrated moments, normalized to remove the dependence on absolute concentration, agree well for all releases. The model $D^{(\mathrm{A}, \mathrm{B}, \mathrm{C})}$ surface centers of mass $\mu^{(\mathrm{A}, \mathrm{B}, \mathrm{C})}$ move seaward with downstream distance, and agree well with observations ( 0.88 skill over all releases). The plume squared cross-shore length scale $\sigma_{\text {surf }}^{2}$ (second moment) is used to estimate bulk cross-shore diffusivity $\kappa_{x x}$. The downstream evolution of model and observed $\sigma_{\text {surf }}^{2}$ is similar, with high skill (0.92).

[57] Mean model $\left\langle\kappa_{x x}\right\rangle_{\mathrm{A}, \mathrm{B}, \mathrm{C}}$ are similar to observed $\kappa_{x x}^{\text {(obs) }}$, with good correlation $\left(r^{2}=0.72\right)$ and skill of 0.40 . Observed $\kappa_{x x}^{(\mathrm{obs})}$ were correlated with a mixing length scaling based on bulk infragravity (IG) cross-shore rotational velocities $\overline{\mathcal{V}}_{\text {rot }}^{\text {(IG) }}$, however modeled $\left\langle\kappa_{x x}\right\rangle_{\mathrm{A}, \mathrm{B}, \mathrm{C}}$ have lower correlation $\left(r^{2}=\right.$ 0.29 ) with this scaling. Alternative mixing length scalings including both IG and very low frequency (VLF, $f<$ $0.004 \mathrm{~Hz}$ ) rotational motions, have higher $r^{2}=0.60-0.63$ correlations with $\left\langle\kappa_{\text {br }}\right\rangle_{\text {A,B,C. }}$. The mean model wave-breaking eddy diffusivity is small and does not effect the bulk dispersion significantly.

[58] The good overall agreement between model and observed tracer plume properties indicates that, given the bathymetry and incident wave field, coupled time-dependent Boussinesq and tracer models can be used to predict surf zone mean tracer evolution and are appropriate for studying the mechanisms of surf zone tracer dispersion.

[59] Acknowledgments. This research was supported by SCCOOS, CA Coastal Conservancy, NOAA, NSF, ONR, and CA Sea Grant. Staff, students, and volunteers from the Integrative Oceanography Division (B. Woodward, B. Boyd, K. Smith, D. Darnell, I. Nagy, M. Okihiro, M. Omand, M. Yates, M. McKenna, M. Rippy, S. Henderson, and D. Michrokowski) were instrumental in acquiring the field observations. We thank these people and organizations.

\section{References}

Clark, D. B., F. Feddersen, M. M. Omand, and R. T. Guza (2009), Measuring fluorescent dye in the bubbly and sediment laden surfzone, Water Air Soil Pollut., 204(1-4), 103-115, doi:10.1007/s11270-009-0030-z.

Clark, D. B., F. Feddersen, and R. T. Guza (2010), Cross-shore surfzone tracer dispersion in an alongshore current, J. Geophys. Res., 115, C10035, doi:10.1029/2009JC005683.

Clarke, L. B., D. Ackerman, and J. Largier (2007), Dye dispersion in the surfzone: Measurements and simple models, Cont. ShelfRes., 27, 650-669.

Csanady, G. T. (1973), Turbulent Diffusion in the Environment, D. Reidel, New York.

Feddersen, F. (2007), Breaking wave induced cross-shore tracer dispersion in the surfzone: Model results and scalings, J. Geophys. Res., 112, C09012, doi:10.1029/2006JC004006.

Feddersen, F. (2011), Observations of the surfzone dissipation rate, J. Phys. Oceanogr., in press.
Feddersen, F., and J. H. Trowbridge (2005), The effect of wave breaking on surf-zone turbulence and alongshore currents: A modeling study, J. Phys. Oceanogr., 35, 2187-2204.

Feddersen, F., D. B. Clark, and R. T. Guza (2011), Boussinesq modeling of surf zone tracer plumes: 1. Eulerian wave and current comparisons, J. Geophys. Res., 116, C11027, doi:10.1029/2011JC007210.

Geiman, J. D., J. T. Kirby, A. J. H. M. Reniers, and J. H. MacMahan (2011), Effects of wave averaging on estimates of fluid mixing in the surf zone, J. Geophys. Res., 116, C04006, doi:10.1029/2010JC006678.

Harris, T. F. W., J. M. Jordaan, W. R. McMurray, C. J. Verwey, and F. P. Anderson (1963), Mixing in the surf zone, Int. J. Air Water Pollut., 7, 649-667.

Henderson, S. M. (2007), Comment on "Breaking wave induced crossshore tracer dispersion in the surfzone: Model results and scalings", J. Geophys. Res., 111, C12007, doi:10.1029/2006JC003539.

Inman, D. L., R. J. Tait, and C. E. Nordstrom (1971), Mixing in the surfzone, J. Geophys. Res., 26, 3493-3514.

Issa, R., D. Rouge, M. Benoit, D. Violeau, and A. Joly (2010), Modelling algae transport in coastal areas with a shallow water equation model including wave effects, J. Hydro-environ. Res., 3(4), 1570-6443, doi:10.1016/j.jher.2009.10.004.

Johnson, D., and C. Pattiaratchi (2006), Boussinesq modelling of transient rip currents, Coastal Eng., 53(5), 419-439.

Kim, D.-H., and P. J. Lynett (2010), Turbulent mixing and passive scalar transport in shallow flows, Phys. Fluids, 23, 016603, doi:10.1063/ 1.3531716 .

Lippmann, T. C., T. H. C. Herbers, and E. B. Thornton (1999), Gravity and shear wave contributions to nearshore infragravity motions, J. Phys. Oceanogr., 29(2), 231-239.

Nwogu, O. (1993), Alternative form of Boussinesq equations for nearshore wave propagation, J. Waterw. Port Coastal Ocean Eng., 119, 618-638.

Pearson, J. M., I. Guymer, J. R. West, and L. E. Coates (2009), Solute mixing in the surf zone, J. Waterw. Port Coastal Ocean Eng., 135(4), $127-134$.

Peregrine, D. H. (1967), Long waves on a beach, J. Fluid Mech., 27(4), 815-827, doi:10.1017/S0022112067002605.

Peregrine, D. H. (1998), Surf zone currents, Theor. Comput. Fluid Dyn., 10, 295-309.

Rodriguez, A., A. Sánchez-Arcilla, J. Redondo, E. Bahia, and J. Sierra (1995), Pollutant dispersion in the nearshore region: Modelling and measurements, Waterw. Sci. Technol., 32(9-10), 169-178, doi:10.1016/ 0273-1223(96)00088-1.

Ruessink, B. G. (2010), Observations of turbulence within a natural surf zone, J. Phys. Oceanogr., 40(12), 2696-2712, doi:10.1175/2010JPO4466.1.

Schmidt, W. E., B. T. Woodward, K. S. Millikan, and R. T. Guza (2003), A GPS-tracked surf zone drifter, J. Atmos. Oceanic Technol., 20, 1069-1075.

Schmidt, W. E., R. T. Guza, and D. N. Slinn (2005), Surf zone currents over irregular bathymetry: Drifter observations and numerical simulations, J. Geophys. Res., 110, C12015, doi:10.1029/2004JC002421.

Spydell, M. S., and F. Feddersen (2009), Lagrangian drifter dispersion in the surf zone: Directionally spread, normally incident waves, J. Phys. Oceanogr., 39, 809-830.

Spydell, M. S., F. Feddersen, and R. T. Guza (2009), Observations of drifter dispersion in the surfzone: The effect of sheared alongshore currents, J. Geophys. Res., 114, C07028, doi:10.1029/2009JC005328.

Tao, S., and T. JianHua (2006), Numerical simulation of pollutant transport acted by wave for a shallow water sea bay, Int. J. Numer. Methods Fluids, 51, 469-487, doi:10.1002/fld.1116.

Wei, G., J. T. Kirby, S. T. Grilli, and R. Subramanya (1995), A fully nonlinear Boussinesq model for surface waves. I. Highly nonlinear, unsteady waves, J. Fluid Mech., 294, 71-92.

Wunsch, C. (1996), The Ocean Circulation Inverse Problem, Cambridge Univ. Press, Cambridge, U. K.

D. B. Clark, Woods Hole Oceanographic Institution, Woods Hole, MA 02543, USA. (dclark@whoi.edu)

F. Feddersen and R. T. Guza, Scripps Institution of Oceanography, University of California, San Diego, La Jolla, CA 92103, USA. 